Portland State University

PDXScholar

1980

\title{
Multiple impact therapy : evaluation and design for future study
}

\author{
Jacqueline $\mathrm{H}$. Abikoff \\ Portland State University \\ Dennis C. Anderson \\ Portland State University \\ Patricia C. Bowman \\ Portland State University \\ Carolyn Crawford Caylor \\ Portland State University \\ Nancy W. Freeland \\ Portland State University
}

Follow this and additional works at: https://pdxscholar.library.pdx.edu/open_access_etds

onext page for additional authors

Let us know how access to this document benefits you.

\section{Recommended Citation}

Abikoff, Jacqueline H.; Anderson, Dennis C.; Bowman, Patricia C.; Caylor, Carolyn Crawford; Freeland, Nancy W.; Godfrey, Jan A.; Graham, Marlene; Hall, Kelly Ann Mason; Hatzenbeler, Mary J.; Hedlund, Susan C.; Kast, Carol Lewis; Lansky, Gayle Matson; Lewis, Janet M.; Muldoon, Kathleen Patricia; Stoudt, Victoria A. G.; and Waage, Anita, "Multiple impact therapy : evaluation and design for future study" (1980). Dissertations and Theses. Paper 3461.

https://doi.org/10.15760/etd.5345

This Thesis is brought to you for free and open access. It has been accepted for inclusion in Dissertations and Theses by an authorized administrator of PDXScholar. Please contact us if we can make this document more accessible: pdxscholar@pdx.edu. 


\section{Author}

Jacqueline H. Abikoff, Dennis C. Anderson, Patricia C. Bowman, Carolyn Crawford Caylor, Nancy W.

Freeland, Jan A. Godfrey, Marlene Graham, Kelly Ann Mason Hall, Mary J. Hatzenbeler, Susan C. Hedlund, Carol Lewis Kast, Gayle Matson Lansky, Janet M. Lewis, Kathleen Patricia Muldoon, Victoria A. G. Stoudt, and Anita Waage 
MULTIPLE IMPACT THERAPY:

EVALUATION AND DESIGN FOR FUTURE STUDY

by

JACQUELINE H. ABIKOFF

DENNIS C. ANDERSON

PATRICIA C. BOWMAN

CAROLYN CRAWFORD CAYLOR

NANCY W. FREELAND

JAN A. GODFREY

MARLENE GRAHAM

KELLY ANN MASON HALL
MARY J. HATZENBELER

SUSAN C. HEDLUND

CAROL LEWIS KAST

GAYLE MATSON LANSKY

JANET M. LEWIS

KATHLEEN PATRICIA MULDOON

VICTORIA A. G. STOUDT

ANITA WAAGE

A practicum submitted in partial fulfillment of the requirements for the degree of

MASTER OF SOCIAL WORK

Portland State University

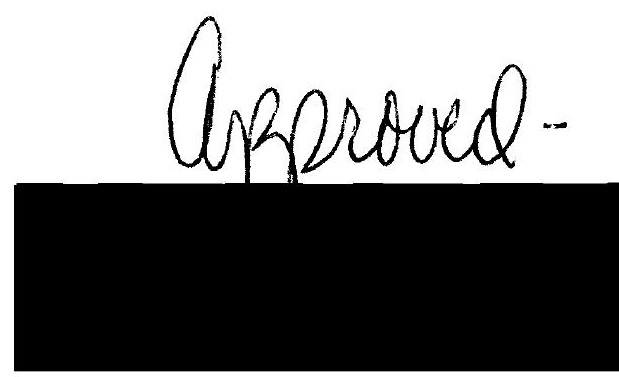




\section{ACKNOWLEDGMENTS}

We wish to acknowledge and thank the Washington County Branch of the Children's Services Division for their willingness to undergo our scrutiny, and for their practical help in providing us with much necessary information.

We are particularly appreciative of the kindness and assistance of William Showell without whom this study would not have been possible.

We are especially thankful to our advisor, Dr. Sandra C. Anderson, whose exceptional leadership and support contributed immeasurably to this project.

For their expert guidance in the analysis of our data, we are grateful to Rosemary Ryan and Elizabeth Shell of the Regional Research Institute for Human Services.

Finally, we are indebted to the eleven families who participated in our study for their willingness to share important segments of their lives with us. It is to the goal of increasingly competent and timely services to such families that this study is dedicated. 
TABLE OF CONTENTS

PAGE

ACKNOWLEDGMENTS

CHAPTER

I REVIEW OF RELEVANT LITERATURE ................ 1

INTRODUCTION ........................ 1

SYSTEMS THEORY OF FAMILY THERAPY .......... . . 1

Role Theory and Families......... 4

Communication Theory and Families . . . . . 10

CRISIS INTERVENTION WITH FAMILIES . . . . . . . 14

ASSESSMENT OF FAMILIES IN CRISIS . . . . . . . . 19

MULTIPLE IMPACT THERAPY . . . . . . . . . . 24

I I HISTORY AND OBJECTIVES .................. . . . 30

II METHODOLOGY ...................... 35

DESIGN . . . . . . . . . . . . . . 35

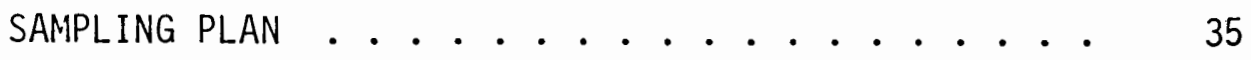

DATA GATHERING METHODS ............ . . . 37

INSTRUMENTS .......................... 37

DATA ANALYSIS PLAN ................... 39

IV FINDINGS ............................... 41

DESCRIPTION OF STUDY FAMILIES ........... 41

OUT-OF-HOME PLACEMENT . . . . . . . . . . . 41

CHANGE IN FAMILY FUNCTIONING . . . . . . . . . 42

CHANGE IN PRESENTING PROBLEMS ......... 43 
CHANGES IN SELF RATING ............... 44

FOCUS OF FAMILY PROBLEMS . . . . . . . . . . . 45

ADDITIONAL COUNSELING AFTER MIT ........ 45

FEELINGS ABOUT MIT EXPERIENCE . . . . . . . . 46

SUGGESTIONS FOR IMPROVING SERVICES ........ 48

SUMMARY AND CONCLUSIONS ................. 49

V CRITIQUE OF THE PRESENT STUDY ................. 51

THEORETICAL FRAMEWORK .............. 51

RATIONALE OF PROGRAM ................. 55

DESIGN AND METHODOLOGY . ........... 56

INSTRUMENTS ......................... 58

Self-Rating Scale ........... 59

Identifying Information Questionnaire... 61

Interview Schedule .......... 63

CONCLUSIONS ............................ 64

VI FUTURE STUDY OF MULTIPLE IMPACT THERAPY ....... 65

RESEARCH PROBLEM .................. 65

DESIGN AND SAMPLING PLAN ............ 66

DATA GATHERING METHODS AND INSTRUMENTS ...... 67

Self-Report Methods .......... 68

Observational Methods .......... 70

BIBLIOGRAPHY ......................... 75

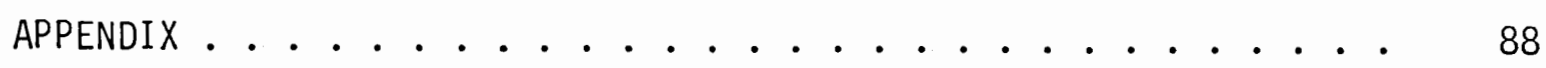

A TABLE 1: Self-Rating Scale: Total Family
Mean of Change Across Items . . . . . . . . . 89

B INTRODUCTORY LETTER . . . . . . . . . . . . 90

C IDENTIFYING INFORMATION QUESTIONNAIRE ......... 91 
APPENDIX

PAGE

D SELF-RATING SCALE . . . . . . . . . . . 95

E INTERVIEW SCHEDULE .................... 96 


\section{CHAPTER I}

\section{REVIEW OF RELEVANT LITERATURE}

\section{INTRODUCTION}

The theoretical underpinnings of Washington County Children's Services Division (CSD) Immediate Conflict-Resolution Family Treatment Program include the systems theory of family therapy with a focus on communication and roles. One of the many approaches to helping families in crisis, it incorporates theories regarding assessment of and intervention in families in crisis. Finally, while it draws upon several different approaches to family therapy, the Washington County program is most closely related to Multiple Impact Therapy (MIT). Thus, a review of relevant literature must address portions of the above enumerated theories that illuminate the thinking behind the Immediate ConflictResolution Family Treatment Program. While each of the four components of the literature review (systems theory, family crisis theory, assessment of families in crisis, and Multiple Impact Therapy) represents a topic area of breadth and complexity, the aspects of each topic area which seem most relevant to Washington County's MIT project have been reviewed.

\section{SYSTEMS THEORY OF FAMILY THERAPY}

The systems theory of family therapy borrows from the concepts of general systems theory in that it views the family as being composed of 
an organized set of interlocking relationships (Ackerman, 1958; Handel, 1967; Parsons \& Bales, 1960). The overall goal of those relationships is the maintenance, via cybernetic process, of a steady state, or homeostasis (Jackson, 1957; Messer, 1970).

Homeostasis is influenced, in part, by the family's exterior boundary, which determines who is not included in the scope of family activity and controls the flow of information to and from the system (Aponte, 1976). In dysfunctional families, boundaries are often too rigid, such that new information or stimuli cannot easily penetrate to allow for creative realignment or growth. On the other hand, the boundaries of a family system may be too diffuse, allowing the family relationships to be too vulnerable to outside influences (Aponte, 1976; Strean, 1971). These two extremes of boundary functioning are called enmeshment and disengagement. All families can be conceived as falling somewhere along a continuum whose poles are those two extremes (Minuchin, 1974).

Within the family system, there may be subsystems composed of (1) a dyad, such as husband and wife, or (2) a triad, such as mother, father, and child (Messer, 1970). Like the total family system, these subsystems strive for homeostasis, thus influencing the interactional patterns of the entire unit (Spiegel, 1960). For example, in a family where the husband and wife are at odds with one another, a child may be used in such a way as to maintain the uneasy but predictable relationship between the parents (Lidz, Cornelison, Fleck, \& Terry, 1960; Satir, 1967). The goal of the family therapist in such situations is to somehow alter the dysfunctional relational patterns, allowing for new, more functional ones to develop. 
Because of the strong homeostatic tendency of an organized system, treatment of one member alone, without the participation of the rest of the family, may result in the family system subverting the individual's progress (Jackson \& Weakland, 1961; Langsley \& Kaplan, 1968). The family therapist, from the perspective of systems theory, concentrates on the interactional patterns of family members and avoids isolating individual members and labeling them "sick."

The interactional patterns on which the systems-oriented family therapist focuses are those observed during family sessions. It is thought that, while the content discussed in a therapy session may be atypical, family members will communicate with each other in the same way that they do outside the sessions. Thus, rather than looking for information about the family's developmental history to help explain its problems, the systems-oriented family therapist identifies rigid rules and stereotyped roles that limit current family interaction, as well as prevent the family from adjusting to its life cycle (Andolfi, 1979).

Within the general framework of the systems approach to family therapy, several different models exist. One emphasizes family roles, citing problems of role enactment as contributing to family pathology (Andolfi, 1979; Hil1, 1965; Lidz, Fleck, \& Cornelison, 1965; Minuchin, 1974; Spiege1, 1960). This perspective will be discussed at length below. Other authors focus on communication skills and patterns within the family, suggesting that in dysfunctional families, information available to the family system is distorted (Be11, 1975; Jackson \& Weakland, 1961; Satir, 1967; Watzlawick, 1966). This perspective, too, shall receive elaboration below. The distinctions between various 
sub-schools of the systems approach, as well as between systems oriented and, for example, psychoanalytically oriented family therapy, are blurred, with many therapists evolving their own styles and methodology.

\section{Role Theory and Families}

One of the basic concepts used in analyzing the family as a system is that of role transaction (Spiegel, 1960). A role is defined as a goal-directed pattern or sequence of acts tailored by the cultural process for the transactions a person may not carry out in a social group or situation. No role exists in isolation, but is always patterned to correspond to the reciprocal role of a role partner. Therefore, the enacting of a role is associated with a set of reciprocal role responses and expectations on the part of other individuals. The responses elicited from others in turn determine further aspects of the role playing on the part of the initiator. Thus, role playing is also a form of communication dependent upon a system of cues, signs, meanings, values, and symbols which are shared by the participants (Group for the Advancement of Psychiatry, 1970).

The nuclear family in our society has a particular pattern of roles with an underlying structural uniformity (Zelditch, 1960). It is within this framework that the child learns the social role behavior and methods of adjustment to different situations he may encounter as an adult (Messer, 1970). Sociologists have long divided family functions into instrumental, or performance roles, and expressive, or emotional roles. While each generation, as well as each family member, is likely to have different needs and tasks within the family organization, anyone in the family may fulfill any of the roles in either category as long as he or 
she feels comfortable in the role (Messer, 1970).

The concept of family role has become a prominent part of the thinking and literature relevant to family therapy. Many therapists utilize the concept in their assessments of family functioning and diagnosis of problems of interaction within the family unit (Strean, 1967). Problems in role enactment may result in role strain or role conflict, thereby upsetting the equilibrium of the family system. Some characteristics of the family role-set that may be attributed to healthy role functioning include: role flexibility (Howe11s, 1975; Howes, 1976; Langsley \& Kaplan, 1968; Messer, 1970; Rhodes, 1977; Scherz, 1967), clear role differentiation and consistent role performance (Flomenhaft, Kaplan, \& Langsley, 1969; Hi11, 1965; Kaplan, 1970; Langsley \& Kaplan, 1968; Mackey, 1968; Nye, Bahr, Bahr, Carlson, Gecas, McLaughlin, \& Slocum, 1976; Pittman, DeYoung, Flomenhaft, Kaplan, \& Langsley, 1966; Polak, 1971; Spiege1, 1960; Zelditch, 1960), democratic leadership and tolerance for differences, especially as regards the different needs of family members (Messer, 1970; Minuchin \& Barcai, 1969; Parsons, 1972; Polak, 1971; Reuben, 1975; Zelditch, 1960), and congruency of role goals and value orientations (Spiege1, 1960). Each of these characteristics and their implications for homeostasis shall be discussed below. Role flexibility is the capacity of family members to shift to a different pattern of behavior, as in play or fantasy (Messer, 1970). Messer notes that in a healthy role complementarity, each partner is resilient and able to take on roles other than his or her own. Some authors suggest that continual opportunity to practice or exercise voluntary role play and encouragement of role shift are prerequisites of growth (Howells, 1975; Messer, 1970). The need to role play or shift, 
which may occur when a family role is vacated through iliness or not fulfilled, as in families with mentally retarded children, can change the family's role patterns dramatically (Hill, 1965; Langsley \& Kaplan, 1968).

When inflexibility and rigidity in role is present, conflict may develop (Howe11s, 1975; Messer, 1970). The more inflexible and stereotyped the family roles or interaction is, the more the likelihood of pathology (Messer, 1970). Frequently, the family with the most inflexibility presents itself as having the most consensus and harmony. It follows that an increase of defensive behavior then appears as adaptive, and flexibility becomes constricted (Messer, 1970).

\section{Clear role differentiation and discrimination are necessary in}

order to maintain the nuclear family as a healthy and stable system over time (Zelditch, 1960). When family members are not in agreement as to the composition of a particular role-set, conflict may arise. An individual may have to perform different roles and also may experience "differing and potentially conflicting constellations of the components within any given role-set" (Eisenstedt, Wintraub, \& Toren, 1967). One or both persons in the role system may not know or have sufficient familiarity with the role expected of him or her. Or, a husband or wife in the midst of a developmental crisis may be unfamiliar with new aspects of the role-set. Thus, strain is placed on role definitions perhaps already fragile. This resulting confusion may be termed cognitive discrepancy (Spiege1, 1960).

Many of the difficulties that escalate into crises involve differences in concept of their respective roles by family members. Hill (1965) suggests conflict between parents and children should be 
understood and studied in terms of these differences in role expectations. For example, if parent and child have conflicting expectations as to which behavior is appropriate to a particular role, or when norms and behavior patterns of one role are inconsistent with those of another role, the stage is set for a crisis (Nye et al., 1976). Thus, a goal of the family therapist is to enable the family to perceive roles as fluid rather than static (Eisenstedt et a1., 1967).

Democratic leadership and tolerance for differences are also hallmarks of health within the family. Emotional life is geared to interaction and each part of a role has within it elements that elicit an answering response from the environment (Messer, 1970). In order for the interaction to be of a positive nature, leadership must be fair and consistent, flexible and tolerant. The better the family members know each other, the more capable they will be in recognizing each other's emotional needs (Messer, 1970). However, in an authoritarian family, members are ruled by an intolerant and unbending parent. This situation results in resentment and hostility. If one member rebels, other family members may project their own rebellious impulses onto this individual, simultaneously punishing him or her for the rebellion. The rebel may stay in this role while the rest of the family can be counted on to blame and punish him or her (Messer, 1970).

Congruency of role goals and value orientations is also crucial for family health. Common understanding and acceptance of each other's roles, goals, and motivations, accompanied by a reasonable sharing of cultural value orientation, are all factors which lead to increased congruency. Failure of a family to share goals and values is so disruptive to the 
family system that it upsets the family equilibrium, requiring an internal readjustment of direction and orientation to bring members toward consensus (Spiegel, 1960). One source of goal discrepancy may be biological differences, such that fatigue, illness, or deficiency of intelligence may cause a restricted capacity for goal attainment. Families with adolescent members, too, are highly susceptible to role strain from goal discrepancy as the adolescent experiments with new and different roles and value systems.

The concept of family roles is useful in analyzing patterns of interaction among family members in therapy sessions. In his experience with disturbed families, Ackerman (1961) found repeated appearance of a special set of emotional mechanisms, and noted that family members take on non-culturally derived roles in a family drama. Some of the common roles adopted by family members in their drama are: harmonizer, dissenter, advocate, challenger, hero, blocker, recognition seeker, blamer, punisher, authoritarian, placater, distractor, supplicant, persecutor, victim, healer, and sick one (Ackerman, 1961; Howells, 1975; Messer, 1970; Satir, 1967).

One role which commonly emerges in dysfunctional families is that of the scapegoat (Messer, 1970). Sometimes the scapegoat role is filled as a result of one family member's prejudicial attack on another (Ackerman, 1961). It is not unusual for a family member to offer himself as a scapegoat or sacrificial lamb in time of family conflict. The scapegoat is sufficiently reinforced for his problem behavior that he continues to exhibit it despite the hostility and anxiety he feels as a result (Messer, 1970). Often when this happens, another family member, or even someone outside the family, adopts the role of healer and rescues the 
scapegoat or victim (Ackerman, 1961). Though the healer may be considered the "white sheep" of the family and the scapegoat the "black sheep" (Ackerman, 1961), the scapegoat may also take on the role of healer or protector for other family members (Messer, 1970; Vogel \& Be11, 1960).

Scapegoating one member of a crisis prone family serves to reduce tension within the system (Messer, 1970; Voge1 \& Be11, 1960). The scapegoated member may begin to express the family's pathology, thereby providing evidence for the family's fiction that their dysfunction is rooted in the destructive behavior of one member (Langlsey \& Kaplan, 1968; Langsley, Flomenhaft, \& Machotka, 1969; Morrison and Collier, 1969; Parsons, 1972; Pittman et a1., 1966). The choice of family scapegoat is related to the sources of family tension. Where value-orientation conflicts exist, the child chosen may be the one who best symbolizes the conflict. Further, the position of the child in the sibling group may become a focus for the parents' own unresolved childhood problems. Another cause for scapegoating may be identification of a child with a parent whom he or she resembles and who is seen as possessing very undesirable traits (Vogel \& Bel1, 1960). Sometimes a child may have a serious physical disease, a striking physical abnormality, or unusually unattractive facial features.

Very often the scapegoated member in a family under stress is an adolescent (Counts, 1967; Homer, 1973; Howes, 1976; Langsley, Fairbairn, \& DeYoung, 1968; McPherson, Brackelmanns, \& Newman, 1974; Parsons, 1972; Patrick \& Wander, 1974; Rhodes, 1977; Scherz, 1967). Many authors note that presenting problems in families with adolescents in crisis often relate to overt sexuality, separation, changes in values, educational tasks, and problems of communication. Authors have posited several 
explanations for the choice of the adolescent as family scapegoat. For example, the adolescent's phase of psychosocial development is, by its very nature, likely to represent a maturational crisis. Hence, he or she is especially vuinerable and may be the first family member to be overwhelmed by internal stresses (Counts, 1967). Rhodes (1977) adapts the Ericksonian model of life stages to the family, discussing families with an adolescent member as characterized by stage-specific problems. Specifically, as Counts points out, the parents are required to adjust to the role redefinition required by the adolescent's burgeoning separation. The adolescent's rapid physical and emotional maturation and half-adult, half-child status are likely to confuse the balance of even well-integrated families, confronting them with the reality of imminent change in family composition. The adolescent's parents may harbor unresolved conflicts from their own adolescence and may project those conflicts onto their child. Furthermore, parents may be too involved in their own maturational crisis, midlife, to deal effectively with an adolescent in crisis (Scherz, 1967; Voge1 \& Be11, 1960).

Thus, the structure and function of family roles provides insight into family interaction. One factor affecting homeostasis in the family system is the success of family members' role enactment. Understanding the significance of family role interaction is facilitated by an examination of patterns of communication in the family.

Communication Theory and Families

The communications approach to family therapy draws from the general body of communications theory in its fundamental assumption that a social unit may be understood by the study of its communication system 
(Greenberg, 1977). Communication may be defined as any behavior that carries a message perceived by someone else. It can be verbal or nonverbal, and may occur without the awareness of the sender. Empathy has been noted to be both a cause and effect of successful communication insofar as it facilitates accurate perceptions of information, cooperation, and self-regulation (Cronkhite, 1976; Egan, 1975). Communication failure may result from ambiguity, when a family member gives verbal and nonverbal cues which contradict one another, or from a double-bind situation, when a paradoxical message implies that the listener should engage in two mutually exclusive behaviors simultaneously (Bateson, Jackson, Haley, \& Weakland, 1956).

The importance of good communication within families is stressed by several authors (Homer, 1973; Kinney, 1978; Luber \& Wells, 1977; Morrison \& Collier, 1969; Rueveni, 1976; Satir, 1967; Scherz, 1967; Smith, 1976). In fact, a study of communication processes within a family can help the family therapist close the gap between inference and observation of family dysfunction, as well as help reveal the relationship between patterns of communication and symptomatic behavior (Haley, 1964; Satir, 1967; Watzlawick, 1966).

Early research efforts in the field of family communication were concerned with showing that each family has a distinct pattern of interaction and that significant differences can be demonstrated to exist between the communication in disturbed and healthy families (Bateson, 1962; Bateson et al., 1956). Families whose communication skills are limited or dysfunctional rarely exhibit clear, straightforward messages between family members. Wahlroos (1974) states that even within the most stable families, feelings of love and concern 
frequently are not communicated effectively between members. Misunderstandings, destructive anger, and repressed affect abound, with unconscious factors often interfering in the communication process for both sender and receiver. Divorces, adolescent runaways, suicides, and other social problems may relate to the existence of poor communication within families (Wahlroos, 1974). Because a family exists as a system in which many experiences are shared, it develops a unique "language" that consists of familiar and possibly idiosyncratic verbal or nonverbal symbols (Boyd, Clark, Kempler, Johannet, Leonard, \& McPherson, 1974).

As family communication patterns become increasingly exclusive, flow of information to and from the system may be restricted. As a result, communication within the family tends to reflect and reinforce cognitive, affective, and behavioral distortions of reality (Boyd et al., 1974). A type of "family fiction" results, with individual members fulfilling innovative roles created within the drama. In a like manner, individual family members make assumptions regarding one another's roles. If these assumptions are not validated or clarified, communication may be further restricted within the family.

Some authors maintain that "crazy" or dysfunctional behavior may result from an individual's failure to develop the skills required to communicate personal needs and desires (Carkhuff, 1969; Grando \& Ginburg, 1976; Satir, 1967). When an individual does not manifest a means for accurately interpreting and perceiving messages, communication and behavior will be confused and inappropriate (Satir, 1967). Furthermore, inadequate communication skills are highly correlated with low selfesteem, submissiveness, loneliness, and anxiety in individuals (Matteson, 
1974; Satir, 1967). Anthony (1973) suggests a positive relationship between communication skills and overall psychological adjustment.

If family pathology is seen as derived from inadequate communication, it follows that therapy may be seen as an attempt to improve communication skills and patterns. Indeed, research indicates that changes in family functioning in the course of family therapy will be shown by a change in communication patterns (Haley, 1964). The concept of training communication skills as treatment is promoted by a number of authors (Boyd et a1., 1974; Egan, 1975; Satir, 1967). Some authors claim that clients learn the skills of good communication from effective modeling on the part of the therapist (Carkhuff, 1969; Egan, 1975; Grando \& Ginsburg, 1976). One of those critical skills, according to Egan (1975), is accurate empathy. Ivey (1971) proposes that empathy can be broken down into such component skills as attending behaviors, reflection of feeling, reflection of content, paraphrasing, and open questions.

In the Satir (1967) model of communication-oriented family therapy, the therapist enters the family system in such a way as to help the family eradicate symptom-producing communication while acquiring new, more adaptive patterns. Anything which helps the family learn can be utilized. Games, exercises, family sculpting, and role playing are some of Satir's techniques. The therapist teaches the family how to check on invalid assumptions, thus clarifying the nature of interchanges made during therapy. The fundamental assumption of this model is that once a family has developed effective communication patterns, it can resolve specific problems by itself.

In summary, each family has a distinct pattern of communication 
that influences and reflects family functioning. Sufficiently dysfunctional communication within a family imposes stress upon the system, possibly upsetting homeostasis and precipitating a crisis. Many approaches to family therapy have focused on teaching families more adaptive communication skills.

\section{CRISIS INTERVENTION WITH FAMILIES}

Although crisis intervention is a widely applied treatment alternative in family crisis situations, a review of relevant literature reveals that its theory and techniques are amorphous and internally inconsistent, and have not been widely researched (Cronin-Stubbs, 1978; Darbonne, 1968; Smith, 1976, 1978, 1979). Nevertheless, the 1iterature does provide some useful information including: definitions of a family crisis, goals and techniques of crisis intervention, examples of innovative crisis intervention programs, and cautions about too heavy a reliance on crisis intervention as a treatment approach.

A family crisis, as defined by most authors, is a period of disorganization and disequilibrium brought about by the inadequacy of a family's ordinary repertoire of coping mechanisms to meet new or increasing stresses. These stresses can be either external or internal to the family system. External stresses, such as natural disasters, loss of employment, illness, or death precipitate crises because of their serious and unexpected nature (Glasser, 1970; Rapoport, L., 1962). While basic to crisis intervention theory, external stresses will not be discussed here, because it is for crises precipitated by internal stresses that MIT is provided in Washington County.

While categorical labels vary, authors generally agree that there 
are three main types of crisis: (a) developmental crises, arising from role dysfunctions in the family (Howes, 1976; Rapoport, R., 1963;

Rhodes, 1977), (b) interactional crises, resulting from dysfunctional communication patterns in the family, and (c) chronic stress induced crises, which are often associated with substance abuse, poverty, and/or social deviance, and may also be related to the stresses which precipitate both of the other types of crises.

A crisis represents a critical point in an individual's social and psychological development (Smith, 1976, 1978, 1979). Depending on how well the crisis is resolved, the family functioning will either improve or deteriorate when the crisis is over. Fortunately, those experiencing a crisis are highly receptive to growth and change (Alevizos \& Liberman, 1976; Darbonne, 1968; Mackey, 1968; Smith, 1976, 1978, 1979). Some authors believe that because struggles with current crisis situations may be linked to previous intrapsychic and family conflicts, crisis intervention can solve not only current problems, but also the earlier, unresolved conflicts (Berlin, 1975). Thus, crisis intervention can be a very powerful treatment modality.

The goals of crisis intervention, realized through teaching families new coping mechanisms and problem-solving skills, are twofold: to help the family regain its equilibrium and to help it prevent such serious disorganization in the future when it experiences such stress. In order to successfully integrate new coping mechanisms, however, family members must, as a group, accept responsibility for their crisis. Authors agree that focusing treatment away from the identified patient toward the family system is one of the most important tasks of family crisis intervention (Berlin, 1975; Langsley \& Kaplan, 1968; Luber \& 
Wells, 1977; Pittman et al., 1966; Reuben, 1975; Scherz, 1967; Smith, 1976).

While all techniques of crisis intervention include teaching family members new coping mechanisms, the skills thought to be important vary according to the theoretical base of the therapist. For example, a behaviorist approach to crisis intervention views crisisprone families as those in which positive reinforcement is rare (Alevizos \& Liberman, 1976). These authors suggest teaching family members both cooperative problem-solving skills and ways of providing one another with positive reinforcement. Other treatment models focus on the constellation of roles in the family (Langsley et al., 1968; Langsley \& Kaplan, 1968). Role functions are examined closely, and intervention focuses upon clarifying and correcting role dysfunction with the goal of promoting greater role synergy. A third set of coping mechanisms frequently taught in crisis intervention is communication skills (Homer, 1973; Kinney, 1978; Luber \& Wells, 1977; Morrison \& Collier, 1969; Rueveni, 1976; Satir, 1967; Scherz, 1967; Smith, 1976). While the strategies cited above rely solely on the therapist as the skills trainer, in family network intervention the therapist teaches one skill, that of soliciting and receiving positive support from the extended family, neighbors, employers, and other community members, which enables the family to learn all the other skills it needs (McGee, 1974; Rueveni, 1976; Speck \& Rueveni, 1977). The variety of coping mechanisms family members can learn from members of their network is thought to be broader and more appropriate to the particular family than those an outsider would teach (Atteneave, 1969).

Another way to increase the input offered to family members is 
through the use of treatment teams. Langsley and Kaplan (1968) advocated the team approach because team members bring to the crisis intervention different strengths and perspectives that allow them to take on different but complementary roles in working with the family. Homebuilders of Tacoma, Washington, further described below, also use a team approach, often initially providing family members individual workers with whom they can air views privately. This is believed to have a calming effect on family members.

Several authors cite comparisons between crisis intervention and short-term, task oriented therapy, suggesting that contracting with a family in crisis is one means for focusing on current problems (Krider, 1969; Lang, 1974; Nelson \& Mowry, 1976; Rosenberg, 1975; Smith, 1976; Stuart \& Machey, 1977). Steps in the task oriented model include: (a) identifying the precipitating event, (b) encouraging the family to express feelings surrounding the crisis, (c) exploring with the family what problem-solving activities they have used and why they failed, (d) exploring alternative means of coping and identifying tasks to be accomplished in acquiring those coping skills, and (e) creating a bridge to other community and natural helping resources (Nelson \& Mowry, 1976; Smith, 1976). Stuart and Machey (1977) point out that the significant difference between task oriented crisis intervention and short-term therapy is that the former approach focuses upon satisfactory resolution of acute distress and disequilibrium, while the latter is concerned with more general patterns of behavior.

Many crisis intervention styles reported in the literature reflect combinations of treatment modalities and innovative responses to gaps in service delivery systems. Utilization of mobile police crisis units, for 
example, was developed in order to reduce the impact of domestic disputes upon the justice system (McGee, 1974; Sullivan, Bodin, \& Everstine, 1977). Trained in teaching basic communication skills and fair fight techniques, these crisis units are often the only local resources available on a twenty-four hour basis and are frequently the first to be called in the event of a family crisis (Sullivan et al., 1977; Wallace \& Schreiber, 1977). Another family crisis project, Homebuilders of Tacoma, Washington, intervenes in families who have begun out-of-home placement proceedings for one member. Their intensive, in-home approach functions, in part, to relieve the burden of other agencies in the community. They have added new dimensions, such as live-in therapists, to crisis intervention.

While family crisis intervention is an innovative and widely accepted treatment modality, it should not be relied upon as the only approach to treating dysfunctional families. LaVietes (1974) points out that crisis intervention and short-term therapy are attractive to many agencies because of their time and cost reducing potential. This poses a danger in that many agencies may be choosing therapies on the basis of expediency rather than appropriateness, especially in the case of poor clients. LaVietes believes that crisis intervention and short-term therapy are inappropriate for families who may be in a constant state of pre-crisis or crisis due to the stresses of prolonged poverty and ghetto life. Strickler and Bonnefil (1974) further caution practitioners against using crisis intervention as a substitute for treatments that are more appropriate for families with chronic psychopathology. Finally, because of the intensity and long hours required in crisis intervention, crisis workers tend to "burn out" frequently (Kinney, 
1978; Kinney, Madsen, Fleming, \& Haapala, 1977). Thus, it is important before using crisis intervention techniques in a family, to understand enough about its members to be able to judge whether or not this is the best treatment approach for them.

\section{ASSESSMENT OF FAMILIES IN CRISIS}

An assessment of a family which is in crisis must fulfill two requirements: first, it must be as thorough as possible; and second, it needs to be carried out as quickly as possible following the request for service. Reuben (1975) stresses the importance of gaining a thorough understanding of the crisis and of its precipitating factors when he says that therapists should "obtain as much information as [they] can . . . [and] completely evaluate the situation" (p. 78). This sort of thorough assessment can be facilitated by the family's heightened anxiety during the crisis period, which can make it easier for members to openly express their feelings (Armsby, 1971). Yet all authors reviewed agree that the intervention should take place as soon after the crisis occurs as possible. Most advocate the avoidance of complex intake screening so that treatment will be simultaneous with diagnosis (Langsley \& Kaplan, 1968; Pittman et al., 1966; Smith, 1978; Stuart \& Machey, 1977; Sullivan et al., 1977). Thus, the task of the therapist is to find a method of assessment that is both thorough and expedient.

While some authors highlight the importance of identifying the crisis causing stress as the first step of assessment (Morris, 1968; Morrison \& Collier, 1969), most authors focus their attention on the family's way of coping with the crisis, rather than on the event itself (Parad \& Caplan, 1960; Mackey, 1968). The variety of coping mechanisms 
cited can be divided into two categories: those which are either individual in nature or have to do with the family's relationship to the larger community, and those which have to do with patterns of family interaction. The first category includes the level of each family member's ego functioning (Berlin, 1975; Counts, 1967; McPherson et al., 1974; Patrick \& Wander, 1974; Rosenberg, 1975; Strickler \& Bonnefi1, 1974). In addition, it focuses on the degree to which the family has a natural helping network which provides it with support (McGee, 1974; Rueveni, 1976; Speck \& Rueveni, 1977). Coping mechanisms relevant to the category of patterns of family interaction include general synergy of the family role set and effective, efficient family communication. It is upon the latter, an analysis of the patterns of family communication, that many family assessments are based.

Many authors agree that the best approach to assessing a family's pattern of communication is to observe family members interacting with one another (Haley, 1964; Parad \& Caplan, 1960; Watzlawick, 1966), rather than merely questioning them about how they communicate. As Levinger (1963) suggests, although family members may modify the content of their interaction when they are being observed, they will not be able to change the process of their communication. Since it is the process, and not the content, that is considered important in a study of family interaction, mere observation of family members communicating with one another can yield rich clinical data (Watzlawick, 1966).

While naturalistic observation of families, often done in their own homes, is advocated by some (Kinney, 1978), and was the predominant mode of early family observations (Haley, 1962), it gave observers data that was merely descriptive in nature, and was difficult to use in comparing 
families. This was a problem both to the researchers attempting to study families through observations and to clinicians, who needed to be able to assess a family's coping mechanisms in order to plan an intervention. Thus, researchers and clinicians began to structure the observational situation more, using a structured interview in. which families were asked the same questions in the same manner (Jackson, 1963; 01son, 1968; Riskin, 1964; Riskin \& Faunce, 1970; Sojit, 1969), using a family task in which members were given a verbal task (Elbert, Rosman, Minuchin, \& Guerney, 1964; Goodrich \& Boomer, 1963; Loveland, Wynne, \& Singer, 1963) or a largely nonverbal task, such as playing (Moustakas, Sigel, \& Scha1ock, 1956; Schulman, Shoemaker, \& Moelis, 1962), or using a combination of these methods (Addario \& Rodgers, 1974; Drechsler \& Shapiro, 1963; Ferreira, Winter, \& Poindexter, 1966).

Though structuring the observations made it easier to compare data obtained from families, it created concern as to whether the situations observed were too artificial to have any meaning (Levinger, 1963; Rabkin, 1965; Vidich, 1956). For example, Rabkin suggested that whereas real situations are complex and filled with ambiguities, the experimental ones were usually rather simple, rarely containing more than one ambiguity. One solution to this dilemma was a combination of structured and less structured techniques, so as to obtain both standard and meaningful data (Levinger, 1963).

Watzlawick's Structured Family Interview (1966), developed as a tool for assessing patterns of family interaction, consists of five separate tasks, the first being the one modified by the Washington County MIT teams for their own use. First, each family member is asked individually, "What do you think are the main problems in the family?" and is told 
that answers will remain secret. The family is then asked to meet as a group and discuss the main problems together and is told that people have different ideas. This portion of the interview serves three distinct purposes: it gives each member the right to his or her own view; it presents the notion that there are more problems than merely the identified patient; and it promotes the idea of a family problem. The second task involves asking the family to plan something together as a unit. The therapist observes whether the family can reach a decision within the specified five minutes, and also looks for emerging patterns of interaction. The third task requires participation of the parents, who are asked, "How, out of all the millions of people in the world, did the two of you meet?" Again, the therapist observes the elicited patterns of marital interaction. Next, the parents are asked to discuss the meaning of a proverb, and then to teach it to their children. This task elicits information regarding the type of learning climate that the parents provide for their children. Finally, all members sit down with the therapist in a circle and are instructed to write down on a card the main fault of the person on their left. The therapist then rearranges the cards, reads the responses, and asks family members, "To whom do you think this applies?" This exercise reveals patterns of scapegoating, favoritism, and self-blame within the family.

Several authors have borrowed specific portions of the Watzlawick (1966) interview or have used modified versions of it for purposes of family assessment or for family research (Jackson, 1963; 01 son, 1968; Riskin, 1964; Riskin \& Faunce, 1970; Sojit, 1969). The rationale for using only a part of the interview is the belief that a few minutes of a family's interaction will reveal their style of communication (Riskin, 
1964; Riskin \& Faunce, 1970). Others have used semi-structured interviews to assess families requesting service (Drechsler \& Shapiro, 1963; Tyler, Truumaa, \& Henshaw, 1962). These interviews consist of asking the entire family group why they have asked for service or what their problem is, and observing their patterns of communication as they discuss the question.

A somewhat different approach to eliciting family interaction is that of presenting the family with some ambiguous stimuli, usualiy in the form of projective tests, and asking them to discuss their ideas about the stimuli and to organize them into a coherent whole. Loveland et al. (1963) used Rorschach cards for this purpose, while Ferreira et al. (1966) used Thematic Apperception Test (TAT) cards in addition to a family questionnaire. Elbert et a1. (1964) also used a projective technique, the Family Interaction Apperception Test, but asked members to respond to it individually, while assessing patterns of family interaction by observing the family discussing and answering six questions. This approach is similar to the structured interviews in that it, too, gathers what is considered clinically relevant content (in this case answers to projective tests rather than opinions about the nature of the family problem) and structures a situation in which clinicians can observe family interaction.

Thus, a structured family interview or a family task can fulfill the requirements of an adequate assessment of a family in crisis. In its brevity, it can be incorporated into the beginning of a therapy session, providing therapists with observational information. It can also provide them with a thorough understanding both of the content of the crisis, either intrapsychic or environmental, as well as an understanding of the 
family's pattern of communication.

\section{MULTIPLE IMPACT THERAPY}

A review of relevant literature reflects the lack of research thus far conducted on Multiple Impact Therapy (MIT). Of the research available, much has been done primarily on a case-study basis. While MIT can be viewed as a form of brief psychotherapy (Goolishian, 1962), it is evident upon closer scrutiny that few authors actually label their approach MIT. Other treatment modalities may seem similar to the MIT approach: Multiple Therapist Therapy (Gray, 1973), Time Extended Family Interviewing (Breslow, 1977), or Multiple Family Group Therapy (Fong, Schneider, \& Walls-Cooke, 1978) are examples. These reflect, however, separate and distinct approaches to family intervention. For the purposes of this study, only treatment approaches that are based on the original MIT model have been considered.

Multiple Impact Therapy is an interventive treatment approach developed in the 1950's to be utilized with families in crisis. It evolved largely from work done at the Youth Development Project of the Neuropsychiatric Department of the University of Texas Medical Branch at Galveston which focused many of its efforts on providing counseling to teenagers and their families and on developing and testing new techniques of intervention. Agnes Ritchie (1960) notes that MIT developed partially from the desire to offer help and hope to troubled adolescents and their families, who in many cases lived in communities where long-term treatment was neither available nor affordable. In addition, it was an attempt to avoid institutionalization of adolescents in crisis. MIT is based on two assumptions similar to those underlying crisis intervention 
with families.

That individuals and families facing a crisis are stimulated to mobilize strength and resources to meet it, and that they are more receptive to interpretations, more likely to be flexible in attitude than at other times. The second assumption is that in any type of psychotherapy there is likely to be faster and more dramatic change in the early stages of treatment, and that under long-range treatment later change and improvement is more gradual. (Ritchie, 1960, p. 17)

Referred to by Robert MacGregor (1962) as a way in which "selfrehabilitating family processes can be mobilized with brief psychotherapeutic intervention" (p. 15), MIT is a brief, usually two-day, intensive study and treatment of a family in crisis. Treatment is ideally implemented by a multi-disciplinary team (drawing from such fields as psychology, psychiatry, and social work), together with all members of the identified family. The rationale behind the utilization of a multi-disciplinary team is the idea that the differing but complementary expertise of the group permits them to see a family, its members, and its problems from many perspectives (Shaw, Fore, Ritchie, McAnulty, \& Nixon, 1977). Other MIT approaches, however, have utilized team members of similar professional disciplines rather than multi-disciplinary (Anderson, Dogoloff, Roy, Swartz, Howard, \& Godfrey, 1979). MacGregor (1964) cites three ideas as central to the concept of MIT:

1. Recognizable patterns of parental interaction are apt to produce and maintain in dynamic equilibrium specific forms of developmental arrest in offspring that issue in various types of behavioral maladjustment in adolescence.

2. Certain types of interaction of the team with itself and the family in crisis may serve as model behavior with which the family may 
identify in its problem-solving efforts.

3. Certain messages of respect from the team to the family concerning the family's predicament and the capacity for change may have favorable impact on the family's self-evaluative and self-revisory functions (family self-rehabilitative processes).

The techniques used in Multiple Impact Therapy are rather flexible and vary somewhat from setting to setting, but essentially consist of an initial family-team conference, followed by a series of individual interviews, joint interviews (two family members with one therapist or two therapists with one family member), overlapping interviews to bridge communication, and the encouragement of discussion among family members; all these procedures being interrupted by formal and informal team conferences and terminating with a joint family-team conference. The aim of the initial family-team conference is to discover gross patterns of family interaction and established communication patterns. The initial interviews are intended to give each family member an opportunity to ventilate grievances, present defenses, and to rationalize their behavior and attitudes toward others.

During the course of the Impact, the treatment team members make interpretations, clarify and restate issues, and draw conclusions. Clearcut impressions of the strengths and weaknesses of each family member, as well as the dominant mode of relatedness, become evident. Distortions and discrepancies come increasingly to light throughout the intervention. The team also interprets family role functioning and can view the meaning of the current crisis in terms of those roles. A treatment plan is formulated by the family and the treatment is based upon the family's potential strengths and capabilities to solve their problems. 
In its initial model, MIT utilized psychological testing of the adolescent in the family, with a psychiatrist as primary therapist to the adolescent and a social worker as therapist to the parents. Since inception, however, MIT has evolved increasingly toward a systems approach to treatment, and reinforces the idea of a family as a set of interlocking relationships maintaining homeostasis. As such, treatment concentrates on interactional patterns of family members and avoids isolation of individual members for treatment.

The basic objectives of MIT are similar to the objectives of all family therapy: to evaluate and modify pathological patterns of interaction, modify the inappropriate roles of family members, and improve communication within the family. Several authors stress the importance of role boundaries within the family (Minuchin, 1974; Shaw et al., 1977), as noted previously. MIT teams frequently discover that the generational boundaries of a given family are diffuse or nonexistent (Shaw et al., 1977). Again, as the goal of MIT is to clarify interactional patterns and facilitate communication within the family in order to change the structure and organization of the family, intrapsychic dynamics of the individual members are recognized, but the information is used while focusing on the present interactions of the family members. Bateson (1962) noted that some of the therapeutic efficiency in the MIT approach may be due to the "cross-monitoring" that occurs in therapy, implying that the person who is being talked about is there and probably listening. Thus, repair of defective communication patterns within the family tends to follow from direct demonstration of communication patterns and skills by team members (MacGregor, 1964). It has been noted that MIT works equally well from a psychodynamic family-therapy point of view and 
from a structural or systems point of view, provided the team and consultant know and use the concepts of boundaries and family subsystems (Shaw et a1., 1977).

Among the limited studies available, MIT has been shown to work effectively with families where parents are divorced (Ritchie \& Serrano, 1974); with single parent or intact families with the identified adolescent problems of chronic running-away, delinquent acting-out behavior, school failures and phobias, and sexual deviations; and with families identified as having pathological conditions that are difficult to treat by conventional means (Ritchie, 1960). This treatment modality is conducive to rapid adolescent behavioral changes, in that adolescents' natural period of growth does not always need more intensive intervention methodologies (Goolishian, 1962).

As noted, much of the research conducted with MIT thus far has utilized a case-study format. However,

Repeat psychological tests and professional evaluations of change or improvement in various areas of individual and family adjustment indicate that the effectiveness of the type of treatment for the limited number of families seen so far is as great (statisticaliy) as the longer types of conventional therapy. (Ritchie, 1960, p. 21)

It has also been noted that the intensive involvement of the family group and the team, without the loss of momentum that can occur between sessions held at traditional weekly intervals, actually diminished a patient's total number of treatment hours. Furthermore, in emergencies where breakdown of the family seemed imminent, MIT often prevented the breakdown (Shaw et a1., 1977).

MacGregor (1962) notes that MIT has been an effective tool for work primarily with families "having a problem with an adolescent where 
the time commitment and the crisis, with the associated reluctance of the family to face further contact with community agencies, might have excluded many from treatment" (p. 24). In 43 of 50 cases treated in the first two years of the program, family self-rehabilitation processes remained effectively mobilized (MacGregor, 1964). MacGregor also notes that while durability of the results of MIT as brief therapy is indicated, for some families it appears that a series of return visits at six week intervals is desirable in the first year.

Thus, the foundations of systems, role and communication, and crisis theories are evidenced in many aspects of MIT. The limited research available regarding the effectiveness of MIT raises more questions than it answers. However, initial studies indicate that it is adaptable to many different settings and can be useful as an interventive technique for family dysfunction. 


\section{HISTORY AND OBJECTIVES}

In a family which is unable to adequately care for or protect one of its children, the traditional professional intervention is to remove the child from the home and place him or her in substitute care. In Oregon, the Children's Services Division (CSD) has stated the conditions under which a child can be placed in such care: (a) the presence in the home of deficiencies or of dangerous conditions, (b) the child's inability to cope with his or her environment, and (c) the child's delinquency. According to CSD, an out-of-home placement occurs when a child is placed in a family foster care, group care, or independent living situation for which CSD has contracted to pay.

Out-of-home placement, however, is believed by many authors to be a harmful solution to the problem of inadequate family care. It is thought that a growing child needs to be able to depend on a stable environment. When a child in a troubled family experiences a major disruption, placement out of the home, the experience is likely to produce at least a temporary setback in psychological growth (Goldstein, Freud, \& Solnit, 1973). Other authors are even more pessimistic. Littner (1956) believes that children who are placed out of their home experience feelings of abandonment, loss, rejection, worthlessness, anger, guilt, and fear of punishment that cause them psychological problems. Reistroffer (1972) suggests that, from the child's point of view, being 
separated from his or her parents is similar to losing them through death. She concludes that all children who are placed out of their homes become disturbed. Thus, while inadequate care in one's own home is undesirable, substitute care is believed to be as bad or even worse.

Many creative projects have been devised to improve the care provided children by their families rather than placing them in substitute care. For example, one experimental program offered supportive services, such as counseling, education, and practical assistance to the families. Intensive provision of these services was found to be effective in reducing the use of foster care without detriment to the well-being of the children (Sauber, 1976). In another program, a team approach by three organizations providing treatment, educational, and recreational services to severely disturbed children and their parents was found to be a workable alternative to residential treatment (Willner, Perry, \& Rhem, 1972). Goldstein (1973) also discovered that an "extended family" approach by an agency using a wide range of social, educational, and clinical services to keep some children in their homes reduced substantially the number of children requiring substitute care; however, this did require a long-term commitment to service provision. Thus, providing services to the entire family appears to be a way to insure adequate care for children without the serious disruption of placement outside the home.

One approach to crisis intervention with families, Multiple Impact Therapy, was initiated in Oregon in 1965 at a Portland residental treatment center. Inspired by the MacGregor model of MIT, this intervention was modified to more closely adhere to the systems approach to family therapy in contrast to the original, more psychoanalytic model. The 
length of MIT was shortened from a two- to two-and-one-half-day intervention to a six- to eight-hour day. The utilization of MIT spread from this agency to others working with children and families, among them a juvenile court service and Children's Services Division. Though MIT was frequently used as a tool for assessing families requesting services, the Immediate Conflict-Resolution Family Treatment Program developed by Washington County CSD was designed to provide families with assessment and treatment simultaneously. The project extended from March 1979 to May 1979.

The Washington County version of MIT consisted of a team composed of one family therapy specialist and three family therapy aides meeting conjointly with the family members in their homes for six to eight consecutive hours at the time of the family's initial contact with CSD. The interview began with a modified version of Watzlawick's (1966) Structured Family Interview. Each member was asked individually and privately the following questions:

1. What is the major problem?

2. What would you like to change?

The team then told the assembled family members that discrepancies were noted in their replies, and asked them to discuss the questions together and to try to come to a consensus. Team members observed the patterns of communication in the family as they talked and it was upon these observations that the team based the assessment of the family in crisis. The remainder of the day was spent in teaching the family new communication skills: paraphrasing, perception checks, and role reversal. These skills were practiced by family members as they discussed the present family crisis and worked together to resolve it. It was hoped that the 
family would incorporate these skills into its communication pattern, thereby enhancing its ability to resolve future family difficulties before they again reached crisis proportions.

Team members included the family therapy specialist, who was a Social Worker II, and three family therapy aides hired under the CETA program. The aides received approximately eighty hours of training from the specialist prior to their first family intervention. This training also included a general orientation to the Washington County Branch of CSD, selected readings on family therapy, and observation of techniques used by the specialist, followed by practice in simulated family sessions.

It is important to note that the Immediate Conflict-Resolution Family Treatment Program departs from the original MIT model in several other ways, In addition to the shortened length of intervention, the Washington County Team worked conjointly with the whole family in preference to the overlapping interviews of the original model. While MacGregor's MIT focused on the content of communication, this approach stressed the process itself, by teaching communication skills. Another feature unique to Washington County was the use of paraprofessional team members in contrast to MacGregor's teams, which included only professionals. Finally, Washington County's MIT was conducted in the family's home in contrast to the MacGregor model which took place in a clinical setting.

The Washington County CSD project had three specific objectives. The first, related to out-of-home placement, was stated in one of the project hypotheses as follows: "The frequency of substitute care placement of children will decrease with the utilization of MIT at the time of the initial family contact with CSD." This objective would be considered 
as having been met if the number of out-of-home placements approved by Washington County CSD during the first six months of the MIT project was fifty percent of those approved between October 1, 1977, and March 31, 1978. Since eighty-one percent of the cases reviewed during the baseline period were approved for placement, a successful outcome would mean forty percent of potential out-of-home placements being approved. When this criterion was chosen, the project was expected to last longer and serve more families than it actually did.

The objective was also contained in a hypothesis of the study: "Family participation in MIT will increase the family's effective problemsolving skills." The outcome of this objective was to be determined by comparing the Self-Rating Scales completed by each family member at the time of the initial contact with those completed ninety days after participation in MIT.

The third objective, to decrease the out-of-home placement, would be realized if the number of placements were reduced. In addition, however, it was hoped that the MIT approach would prove to be less costly than out-of-home placements. Costs of the program were projected at $\$ 41,000$ for the first year. In contrast, the projected cost of placing twelve children in substitute care for nine months was $\$ 86,400$. Thus, if successful, the Immediate Conflict-Resolution Family Treatment Program would not only provide families with a form of treatment preferable to out-of-home placement, but also would save public funds. 


\section{CHAPTER III}

METHODOLOGY

DESIGN

This descriptive study of the Immediate Conflict-Resolution Family Treatment Program is the first known attempt to systematically evaluate an MIT program. This particular design was chosen because originators of the program had developed the hypotheses prior to this study, and because the sampling and preliminary data gathering were conducted by Washington County CSD for its own purposes before the study began.

This pilot study employs a traditional one group pretest-posttest design. The independent variable is the provision of MIT to families. The dependent variables are: (a) whether the identified patient (IP) was placed out of the home following MIT and (b) whether problem-solving skills used by family members increased following MIT.

\section{SAMPLING PLAN}

The sample, consisting of the thirteen families who received MIT, was drawn from the population of families requesting services from or referred to the Washington County Branch of CSD between March 19, 1979, and May 14, 1979. Several criteria were utilized for sample selection. First, requests for service included in the population were for "help," "counseling," and "out-of-home placement." Requests could come either from a family member or from a third party to whom a family had gone for 
one of these services. Families describing the following problems were included in the population: beyond parentai control, truancy, suspected nonsexual abuse of a child twelve years or older, family conflict, delinquency, a drug or alcohol problem on the part of the child, or physical violence by the child. Families requesting the following kinds of service were not included in the population: home study, protective services, medical assistance, day care, environmental assistance, parenting assistance, mentally retarded or developmentally disabled children, or money management. The family problems included in the population were those thought to have the greatest potential for bringing about out-ofhome placements.

The sampling plan for this study can be most accurately described as quota sampling, a non-probability technique. The sample was drawn weekly as the project team reviewed the intake log to find those families who fit their criteria for inclusion in the project population. Out of the several families requesting service each week who fit the criteria for inclusion in the MIT project population, only two or three could be seen by the project staff. The intent was to perform MIT with the first appropriate families who requested service during the week.

No control group was used in this study; however, the families in the CSD population who received regular casework services during the same time period formed a natural comparison group. Thus, statistics from the sample receiving MIT were compared with those from the comparison group which comprised the remaining population of this study. 


\section{DATA GATHERING METHODS}

Data for the present study were gathered with three different instruments: the Identifying Information Questionnaire (IIQ), the SelfRating Scale (SRS), and the Interview Schedule (IS) (see Appendices, p. 91 , p. 95, p. 96). The Identifying Information Questionnaire and the Self-Rating Scale were designed and administered by the Washington County CSD; the Interview Schedule, by the research group.

Because of the research design, the IIQ and the SRS were administered twice: once, for pretest, on the day of the MIT experience; again ninety days later, for posttest. The pretest was administered in person by treatment members prior to the start of the MIT. The posttest was mailed to participants by CSD with a request to complete the forms and return by mail.

\section{INSTRUMENTS}

The IIQ, two pages pius a cover sheet, was designed to obtain information about the nature of family problems and of CSD services provided, as well as identifying information. The cover sheet provided a brief explanation of the purpose of the IIQ and the SRS and included an area to indicate who completed the IIQ. Information requested on this instrument included identification of each family member by relationship, age, sex, level of education, and employment status. Other information sought here pertained to out-of-home placement or return of any family members, income level, problems leading to CSD contact, and resolution or expected resolution of these problems. Finally, families were asked to describe the general nature of their problem(s). One questionnaire was 
completed for each family, generally by one family member, in both the pretest and posttest phases.

The SRS was completed by each family member who participated in MIT. Each SRS included an area for identification of the member in terms of family position, age, and sex. Questions asked pertained to the individual's participation in the family with an emphasis on communication. A six-point scale of responses was provided, ranging from "very little of the time" to "almost all of the time." Participants were asked to respond to the questions by checking the statement on the scale which best described how they saw themselves.

The final instrument used to gather data for this study was the Interview Schedule, administered by the researchers to supplement the posttest. The IS was designed to obtain additional data regarding family members' perceptions of change in the family since MIT and their feelings regarding the MIT experience. Interviews were conducted in person by two researchers, most often in the family's home. Each family member met individually with one of the researchers. Family members who had not participated in the MIT were invited to be interviewed and some accepted. The Interview Schedules were completed by the researcher in the presence of the family member, who was given an Is to follow. Some of the questions were structured; however, additional comments made by the family members were noted. Other questions were open-ended, and answers and/or comments were recorded in the space provided. It was the intent of the researchers to obtain precise and individual attitudes and feelings of family members. 


\section{DATA ANALYSIS PLAN}

Two methods of analysis were used in this study: statistical and descriptive. While the SRS was treated statistically in its entirety, only questions six through eleven on the IS were analyzed in this manner. This method was adopted because these six questions directly relate to the five questions on the SRS.

A family mean score was obtained for each "before" and each "after" item on the SRS. A two tailed $\underline{t}$-test was then performed to measure the significance of family change for each item.

Next, sums of scores for all items on the pre- and post-SRS were obtained by each family and a mean family score was calculated for each. A two tailed $\underline{t}$-test was then performed (resulting in eleven $\underline{t}$-tests, one per family) to measure individual family change and the direction of that change, with disregard to individual items. These same cumulative scores were tallied for the total number of individuals in the sample ( $\underline{N}=47)$ without a breakdown by family, and a total mean was determined. A two tailed $\underline{t}$-test was again performed on this total mean score for individuals in order to measure overall group change, again with disregard to items. The individual scores on items six through eleven of the IS were tallied by family and a mean family score was calculated. These mean scores were then compared to the family mean scores for change on the SRS. The intent of this procedure was to identify trends and evaluate whether any change indicated was consistent over the two instruments.

The remaining items on the IS were analyzed descriptively, with special emphasis placed on identifying patterns and trends across family groups. This data could not be analyzed statistically, but was included 
to clarify and supplement the data gathered on the SRS. 


\section{CHAPTER IV}

\section{FINDINGS}

\section{DESCRIPTION OF STUDY FAMILIES}

All thirteen families who received MIT were asked to participate in the present study. One family refused to participate and another could not be located. A few individual family members also chose not to participate. However, overall the families seen were cooperative during the interviews.

There were six female and five male identified patients in the eleven families studied. Among the siblings, there were ten males and ten females. The age range for mothers was 18 to 50 years $(\bar{X}=39.6)$; fathers, 23 to $55(\bar{X}=39.6)$; IPs, 18 months to 16 years $(\bar{X}=12)$; and siblings, 9 months to 18 years $(\bar{X}=10.2)$.

The educational level of the parents ranged from 11 to 15 years for mothers $(\bar{X}=12.5)$ and from 12 to 18 years for fathers $(\bar{X}=13.8)$. A11 fathers in this study were employed and six mothers were employed outside the home. Two families reported an annual income of below $\$ 10,000$; five, between $\$ 10,000$ and $\$ 19,999$; two, between $\$ 20,000$ and $\$ 29,999$; and two, above $\$ 30,000$.

\section{OUT-OF-HOME PLACEMENT}

Of the total thirteen families provided MIT, three (23\%) identified patients were placed out of the home by CSD. Only two (18\%) of these 
participated in this study. Of those two families, three of the four parents and one of the IPs felt the placement was helpful to the family. In the comparison group, receiving conventional CSD services, 24 (37\%) of the IPs out of a total of 65 families were placed out of the home by CSD.

It was also noted that four separate runaways have occurred within three of the families since MIT. Not all of the runaways were IPs. In addition, another child was placed out of the home by the family after MIT. In a11, five (45\%) of the eleven families in our follow-up study were affected by temporary or permanent absence of one family member after MIT. These findings would seem to challenge the hypothesis that MIT averts family breakdown and out-of-home placement.

\section{CHANGE IN FAMILY FUNCTIONING}

Family members were individually asked to rate changes in their respective families since MIT. The rated items, found in Questions 1-4 of the IS, included the way in which the family gets along, the usefulness of learned communication skills, changes in presenting problems, and the overall effect of MIT on the family. Ratings ranged from "much change for the worse" (1) to "much change for the better" (5).

Analysis of the data gathered on these items reflects several trends. Foremost, only a slight overall positive change (3.75) was noted when mean scores were calculated for all families on all four items. Overall scores ranged from the high of 4.75 to a low of 3.1 . When overall means of the four items were calculated by role (i.e., mother, father, IP, siblings), IPS' scores showed the least positive movement (3.43); siblings, the most positive (4.12).

In each of the four items, only a slight positive movement was 
noted. Parents' mean scores were higher than their offspring's on the first three items listed above. Children, on the other hand, out-scored their parents (4.09 vs. 3.55$)$ in terms of the effect of MIT on the fami1y. In other words, parents as a group reported that the MIT experience had slightly more than "no effect" on their problems; while children reported their family problems "got somewhat better" as a result of the MIT experience.

\section{CHANGE IN PRESENTING PROBLEMS}

Question 12 on the IS asked family members to rate how their presenting problems had changed for them since MIT. A five-point scale was utilized, ranging from "much change for the worse" (1) to "much change for the better" (5). The mean response of mothers was 3.72; of fathers, 4.13; of IPs, 3.37; and of siblings, 3.65. Thus, fathers perceived most positive change in presenting problems and IPs least. When analyzed by family, ratings ranged between 2.6 and 5.0, with a mean of 3.64 for a11 families. Six (55\%) of the families reported "no change" in presenting problems. When analyzed by specific problem, 89 (77\%) of the 115 responses indicated "no change," "some change for the worse," and "much change for the worse."

Family members were also asked to identify additional problems that concerned them prior to MIT, but not mentioned on their initial IIQs. Fourteen additional problems were identified by fourteen individuals, and the range of the rated changes was one to five. Two (14\%) problems were rated as showing "much change for the worse," one (7\%) showed "some change for the worse," five (36\%) showed "no change," three (21\%) showed "some change for the better," and three (21) showed "much 
change for the better." It can be concluded from this that MIT had little or no positive effect on these identified additional problems.

\section{CHANGES IN SELF RATING}

The SRS administered to sample families before and after the MIT experience contained five items designed to measure different aspects of communication. An analysis of data gathered by this instrument revealed no significant change in overall family communication skills. Specifically, family mean change by item on the "before" and "after" scales was not statistically significant. In addition, when the total "before" and "after" self-rating scores for each family were compared, with disregard to items, there were few significant differences at a .05 level of confidence. Of the 11 families in the sample, only three showed significant change--two positive and one negative. (See Table, Appendix p. 89.) Similarly, in comparing total individual means before and after, with disregard to item and family group $(\underline{N}=47)$, no significant changes were noted $(p=.20)$.

Items six through eleven on the IS were intended to measure change in communication skills following MIT. A composite of family mean scores for all items revealed little or no change. It is important to note that inconsistencies exist in overall patterns of change indicated on the SRS as compared to the IS. While slight (statistically insignificant) changes appeared for eight families on the SRS, no change was noted for these same families on the IS. Only two families showed little or no change on both the SRS and the IS, and data from one family was distorted because some members did not answer the interview items. The general trend, then, is of little or no change in communication skills. 
FOCUS OF FAMILY PROBLEMS

One of the goals of most forms of family therapy is to shift the focus of the family problems from the IP to the entire family. In an effort to determine if this occurred in the program being evaluated, family members were asked whether they felt any member(s) of the family were the cause of family problems or whether the entire family was involved. There were 44 responses to this question, 20 parents and 24 children. Of these, 12 parents and 12 children responded that the entire family was involved. Of the adults and children who responded that the entire family was not involved, $15(75 \%)$ felt that either the IP or the IP and one other family member were responsible for the family's problems. The remaining 5 responses pointed to a variety of family members as the cause of problems.

Thus, only $24(54 \%)$ of 44 respondents felt that the entire family was involved in current family conflicts. The other 20 people felt that one or more family members were responsible for their family problems. It can be said, therefore, that MIT was minimally successful in shifting the focus of family problems away from an individual family member.

\section{ADDITIONAL COUNSELING AFTER MIT}

Nine of the eleven families studied said that a member or members had received additional counseling after MIT. Six of these families were no longer receiving counseling at the time of the follow-up interview, while three families were still involved in counseling. Approximately forty-two hours of individual counseling were received, mostly by IPs, in contrast to thirty-three hours of conjoint family counseling. Family 
members received a total of approximately seventy-five hours of post-MIT counseling. In summary, nine of the eleven families studied had received additional counseling following MIT, with the majority of the counseling hours being provided to individual family members, most frequently the IPs .

\section{FEELINGS ABOUT MIT EXPERIENCE}

In answering the question, "How do you feel about your experience with MIT?" 25 (57\%) of the 44 respondents gave positive responses. Mothers were, as a group, the most positive; fathers, somewhat less so; siblings, slightly positive; and IPs, negative in their subjective responses to MIT. While three families were unanimous in their responses, two being positive and one negative, the other eight families had mixed responses to this question.

Respondents expressing positive feelings about their MIT experiences typically said that it improved family functioning, that it made them feel better, or that they appreciated the team members. Several felt that MIT helped family members learn how to accept and understand one another. Specific portions of the experience thought to be useful were the teaching of communication skills and role playing. One respondent liked having the problem redefined as a family problem rather than an individual one. Mood changes were noted by one person who described MIT as providing a new outlook and by another who said it eliminated anger. A respondent mentioned that meeting with the team at home was more comfortable than meeting in a clinical setting. Another said it was a wonderful experience. Team members were described as being helpful, sincere, and professional. The attention of four people at a time of 
crisis was thought to be particularly helpful. Thus, respondents who said they liked their experiences cited as reasons its helpfulness in changing family relationships or individual moods and the positive qualities of team members.

Neutral or mixed responses to the question included several from respondents who felt that MIT is a good idea, but that it had not been helpful to them. For instance, two people thought the experience was "okay," but that they had needed additional help with their problems. More general responses included that of the person who did not like the experience but liked the team members. Another felt MIT had been helpful but might not help all families. Finally, one rather impartial comment was that MIT was "worth a try."

The two weaknesses most frequently cited by those who disliked their experience with MIT were that it did not address their concerns and that they felt one person was blamed for the family's problems. Several people said the problem they identified was not discussed. Other respondents said their family problems were too serious and long-standing to be changed in one day of therapy. Still another said MIT seemed to help for a week but then "everything went back to normal." A number of respondents felt singled out and blamed for the difficulties in their families, while one person worried that this had happened to another family member. Another thought MIT might have been more effective had one family member not been absent during the session. One respondent found the experience "boring." Finally, several family members and one entire family refused to be interviewed, implying they had negative feelings about their experiences with MIT. 
Suggestions for improving CSD services were made by some members in ten of the eleven families, with the majority of the suggestions coming from parents. The most frequent suggestion indicated a need for more follow-up services. Several families noted that additional counseling in general would have been helpful. In other cases, additional MIT sessions or parent training were thought to be necessary. One subject noted that the time pressures of a one-day session may have interrupted the process of significant interactions. Another suggested that a written summary of the MIT session and a follow-up letter would have served as a useful reminder of the skills learned. A telephoned progress check within a few weeks of the MIT experience was thought to be important in another case.

Several suggestions related to improving CSD agency organization and service delivery. One subject noted that standardized procedures in all state branches of CSD would increase the effectiveness of transferred workers. Another response to this item pointed out that having several successive caseworkers prevented continuity of service. Training caseworkers and team members to be more diplomatic and considerate, less authoritarian and hostile was also suggested. On the more positive side was a suggestion that CSD advertise their services. One respondent called for increased funds for MIT, while another thought this treatment mode should be standard for all families. 


\section{SUMMARY AND CONCLUSIONS}

This study included eleven of the thirteen families who received MIT from Washington County CSD. The first hypothesis, that MIT would decrease the number of out-of-home placements, was supported by the study. The families who received MIT had a lower percentage of out-ofhome placements than a comparison group of families receiving conventional CSD services (23\% vs. $37 \%$ ). However, the sample studied was so small that the significance of this finding is reduced.

The second hypothesis, that MIT would increase the family's effective problem-solving skills, received minimal support in this study. On self ratings of communication skills, there were no significant differences between "before" and "after" ratings of all subjects. When analyzed by individual family, two families showed significant positive change and one showed significant negative change. When changes in specific presenting prablems were analyzed, the majority $(77 \%)$ were rated between "no change" and "much change for the worse." Overall, families" mean ratings (3.64) were between "no change" and "some change for the better." Fathers perceived the most positive change in presenting problems; and identified patients, the least. Overall change in family functioning was rated 3.75 , indicating a slight change for the better. Mothers expressed the most positive feelings about the MIT experience; IPs, the most negative feelings about it. Overall, $57 \%$ of the subjects felt the experience was a positive one.

An underlying assumption of MIT is that it helps change the family members' perception of their problems from seeing them as caused by an individual member to viewing all family members as being involved. In 
this study only $24(55 \%)$ of the 44 respondents felt that all the family members had been responsible for the family problems. Although the focus of family problems before MIT is unknown, it is clear that MIT was not successful in shifting the focus away from an individual member in $45 \%$ of the cases.

Ten of the eleven families offered suggestions for improvements in CSD services. The majority of these ideas concerned the need for postMIT counseling and follow-up services. In fact, nine of the eleven families interviewed sought counseling after MIT. This accentuates families' perceptions that MIT alone was not sufficient to help them deal with their problems.

of the thirteen families who received MIT, three had formal outof-home placements. One of these three families refused to participate in this study. The two who did participate were the only families indicating "some change for the worse" in their presenting problems. The mean responses for these two families to questions showing change in family functioning were lower than the mean responses for all families. In addition, these two families had the lowest mean scores on both "before" and "after" Self-Rating Scales. It was noted that parents in these families had more education than most other parents in the study.

In conclusion, the thirteen families who received MIT showed a lower incidence of out-of-home placements than those who received traditional CSD services. On the other hand, minimal overall change for the better was reported in families' problem-solving skills. Of particular note is that the majority said that their presenting problems got worse following MIT. Overall, it seems that MIT had very little positive effect on the eleven families studied. 
CHAPTER $V$

\section{CRITIQUE OF THE PRESENT STUDY}

In order to interpret the findings of the present study, it is important to understand its limitations and strengths. In the following section, the researchers will examine the hypotheses and their operationalization, the major guiding concepts behind the hypotheses, the research design, sampling plan, data gathering methods, and the instruments. The implications for the study's validity, reliability, and generalizability will also be discussed.

\section{THEORETICAL FRAMEWORK}

The original design for this study was in the form of a grant proposal. It is important to note that the original intent of the information compiled by Washington County CSD was for the purpose of securing funds to implement their Immediate Conflict-Resolution Family Treatment Program. Thus, the terms contained within the hypotheses were not defined and operationalized in the manner required to meet the rigorous standards of research. A closer examination of these definitions follows.

Out-of-home placement. Although this definition should have specifically included institutionalization, it was adequately defined for use in this study. There is much research to show that out-of-home placement does indeed have a negative impact on children (Goldstein et al., 1973; Littner, 1956; Reistroffer, 1972), thus a method of minimizing the practice would be of great value. The assumption used in the program 
under review is that it is always best to avoid out-of-home placement. However, it seems likely that there are some families where removal of the child might be the treatment of choice; for example, an older adolescent might benefit from emancipation. According to Reuben (1975), a family should be assessed fully during the intervention, before a specific plan is made. In practice, Washington County CSD began the intervention (MIT) procedures with preconceived goals regarding out-of-home placement.

Initial family contact. One of the hypotheses states that MIT should occur "at the time of initial family contact." However, the definition of "at the time" is not clearly specified, thus it can be interpreted in a variety of ways.

Utilization of MIT. Washington County CSD utilized a model of MIT that is based on but departs considerably from the MacGregor mode1 of MIT. However, in the researchers' view, their basis for departure is not always clearly substantiated. For example, the Washington County model is approximately eight hours long, whereas the MacGregor version lasts two and one-half days. The researchers question the effect of the shortened version on the outcome of the treatment. Given that a structured family interview sometimes lasts two hours or more, the remaining time might not be sufficient to accomplish the treatment goals.

Another departure from the MacGregor model is in the composition of the team. The Washington County team consisted of one social worker and three CETA paraprofessionals, while the original model emphasized the importance of using a team of professionals from a variety of disciplines. In addition, the paraprofessionals on the Washington County team were given eighty hours of training to prepare them for performing MIT. 
There is no rationale in the proposal for either the change in team composition or for the amount and kind of training given the paraprofessionals.

In addition to departing from the MacGregor model of MIT, the Washington County version of a structured family interview differs significantly from Watzlawick's (1966) version on which it was modeled. There is support in the literature for using only one section of the Structured Family Interview in family research (Jackson, 1963; 01son, 1968; Riskin, 1964; Riskin \& Faunce, 1970; Sojit, 1969), but there is no support for significantly altering the content of the extracted section. The portion modified by the Washington County team originally consisted of asking individual family members the question, "What do you think are the main problems in the family?" (Watzlawick, 1966, p. 257). The implications of this question are that each member's view is important; that the therapist assumes the presence of a variety of problems, not just the identified patient's symptoms; and that those problems are related to the entire family (Watzlawick, 1966). The Washington County team changed this question to, "What is the major problem?" and, "What would you like to change?". losing in translation all the implications of the original question and adding an emphasis on change which, in the researchers' opinions, is of questionable usefulness in the first few minutes of the intervention.

Family participation. Family participation was not defined in the original proposal, leaving many questions unanswered: (a) must all family members be present? (b) how is a family member defined, other than nuclear family members? (c) does participation mean more than mere physical presence? (d) can a family member be considered to be participating 
if under the influence of drugs or alcohol? and (e) must family members be present throughout the entire MIT experience to be considered participants? Given the lack of definition, the concept of "family participation" is unreliable. Furthermore, the variation in proportion of family members participating in the thirteen impacts hampers the validity of this study.

Problem-solving skills. Although the term "problem-solving skills" is not specifically defined, the proposal refers to the communication skills of paraphrasing, perception check, and role reversal, implying that these are "problem-solving skills." Does the acquisition of these skills alone necessarily mean that one will become proficient in problemsolving for present and future conflict issues? Poor communication skills are often cited as a problem in families (Anthony, 1973; Carkhuff, 1969; Grando \& Ginsberg, 1976; Satir, 1967), but rarely as the only problem. By focusing on such skills to the exclusion of others, the Washington County team may not be using the crisis as an opportunity to buttress other types of coping mechanisms in the family. Again, the researchers believe that assessment is necessary before assumptions can be made about the fundamental nature of the problems and treatment of any given family.

The Washington County program emphasizes interactional process over identified problem content. The teaching of specific communication skills to family members is a common element found in the therapeutic repertoires of several authors (Boyd et a1., 1974; Egan, 1975; Satir, 1967). Given that this is an important variable, it is essential that such teaching actualiy occur. The design of this study renders it impossible to evaluate the extent to which this teaching did occur.

An assumption evident in the proposal hypotheses is that improving 
communication skills among family members will prevent family dissolution. While improving such skills can be seen as positive, it seems quite possible that such improvement could lead to an awareness that family breakup is a realistic resolution of the problem. Thus, an improvement in communication skills does not necessarily lead to a desire to maintain the family unit. The researchers question the rationale for the hypotheses, which state in effect that MIT will lead to stabilizing family units via improved communication skills.

\section{RATIONALE OF PROGRAM}

There is a substantial amount of research which supports the need for a program like Washington County's. Families with adolescents are subject to particular types of stresses (Counts, 1967; Rhodes, 1977). MIT was developed in part to answer the needs of these families; the Washington County mode $\mathrm{l}$ is in keeping with this tradition.

The Washington County model purports to treat families in crisis, thus relying on crisis intervention theory. While crisis intervention is a technique widely advocated (Berlin, 1975; Langsley \& Kaplan, 1968), some authors caution against viewing it as a panacea for all types of family problems (LaVietes, 1974; Strickler \& Bonnefil, 1974). Strickler and Bonnefil (1974), in particular, note that its use with families manifesting chronic pathology is contraindicated. However, the Washington County program makes no attempt to differentiate between chronic and acute family problems. In fact, the screening criteria do not stipulate crisis at al1. Instead, the commitment is made to crisis intervention as a treatment modality prior to an assessment of its appropriateness for the particular family involved. Once again, the need must be stressed 
for adequate evaluation before commitment to any type of treatment is made.

The Washington County proposal states that MIT is less expensive than out-of-home placement. Two points relating to the cost effectiveness issue are: (a) would the method still have been cost effective had professional workers been used on the team? and (b) how was the average monthly cost figure for out-of-home placement computed? If, in this computation, equal weight were given to all types of placements, the figure derived would be somewhat inflated. In practice, foster care, the least expensive form of substitute care, is the one most frequently used.

\section{DESIGN AND METHODOLOGY}

This study employs a one group pretest-posttest design in which the independent variable is MIT and the dependent variables are (a) "out-ofhome placement" and (b) "increase in problem-solving skills." Originally, the intent was to utilize two groups, experimental and control. However, it was necessary to forego the control group because of a low response rate among the families contacted. The decision was made to compare the data on the experimental group with CSD data on families who had received traditional casework in the same time period. For purposes of this study, the one group pretest-posttest type of design was an appropriate choice, given the unavailability of a control group.

The absence of a control group and of a random sample pose several problems with validity for this study. Without a control, or "no treatment," group, one cannot ascertain whether findings are attributable to the independent variable or to extraneous variables such as history, maturation, and testing effects. Further, the generalizability of the 
findings is hampered by the lack of a randomly allocated sample. Furthermore, CSD's plan to employ a quota sample in place of a random sample was subverted by two factors. First, the team only had one afternoon to schedule all its MIT interviews for the next week. If the first families on the list could not be reached during that afternoon, team members continued calling other families in chronological order until the interview slots were filled. In addition, during the review of the intake log, CSD intake staff often commented about the appropriateness of particular families for MIT. Although the team tried not to let these comments bias their selection of families, they admit having chosen some families in the sample based on the advice given them. Thus, inferences drawn from the families studied and applied to families in Washington County with similar problems are tenuous at best.

The MIT team itself administered the pretest Self-Rating Scale, and did this on the day of the MIT experience. These factors may have introduced bias into the participants' responses as well as altered their subjective experiences of MIT. Also, the posttest SRS was mailed to participants ninety days later with instructions to return the completed form. Because no one was present during the posttest to supervise the administration of the SRS, one cannot be sure about the conditions under which it was filled out, whether family members answered the SRS individually, in privacy, as a group process, or whether family members influenced each other's responses. A further problem arising from the mailing of the SRS to the sample families is the time lapse between the MIT and the actual completion of the instrument. Because the families were left to respond to the SRS on their own and were not instructed to return it within a specific period of time, different time intervals exist between 
individual families' participation in MIT and their return of the completed instrument. Hence, the administration of the pre- and posttest was not sufficiently uniform or standardized.

Unlike the SRS, the Interview Schedule was administered verbally by a member of the research team to each person in the sample on an individual basis. One problem in the use of an interview schedule for gathering data is the introduction of the additional variable of interviewer style. Some interviewers offered much interpretation of questions, while others adhered closely to the structure and wording of the schedule. This problem could have been alleviated somewhat by more extensive training of the interviewers in the use of the IS. Also, any measure or interpretation of change based on the IS is purely subjective since baseline data from the IS was not collected before MIT. These problems weaken both the reliability and validity of the study.

Another methodological problem was the lack of standardization of the MIT experience. The number of hours in treatment varied from family to family, and it is possible that the content and sequence of events varied during the experimental group's MIT experiences. Subsequent counseling and contacts with CSD and outside agencies make it difficult to ascertain what changes resulted directly from the MIT experience as opposed to other therapeutic interventions.

\section{INSTRUMENTS}

The instruments used to gather data for this study were the SelfRating Scale, the Identifying Information Questionnaire, and the Interview Schedule. The SRS and accompanying IIQ were provided by Washington County CSD. The IS was developed by the researchers in order to 
supplement and clarify the information provided by the aforementioned instruments. The addition of the IS was made necessary by a number of shortcomings in the SRS which will be discussed below.

\section{Self-Rating Scale}

Although the SRS was provided for this study by Washington County CSD, it is not at all clear where it originated, how or by whom it was developed. As a result, it is impossible to determine whether or not the SRS is a reliable and valid instrument.

There are a number of problems in the structure of the instrument that cast some doubt on its validity as a measure of change. The SRS presents six possible responses to each question, thus responses are recorded on a scale which has no neutral midpoint. Respondents could be forced into making a negative or positive response by the absence of a neutral point. Furthermore, the possible responses are vague and overlapping. For example, it may be difficult to discern a clear difference between "some of the time" and "a little of the time." As a result, it becomes unclear whether a given response is due to an arbitrary choice between ambiguous alternatives or an accurate reflection of the respondent's perceptions. In addition, the numerical sequence (1-6) assigned to the scale of possible responses implies equal intensity of the response intervals. However, the working of the scale headings does not reflect an equal progression in intensity of responses. For example, "very little of the time" (1) and "almost all of the time" (6) are not equally opposite concepts. Thus, equal weight cannot be given to responses made at opposite ends of the scale.

Similar problems exist with questions \#3, 4, and 5 of the 
SRS. In each one of these questions two independent concepts are presented, yet only one response is solicited.

Question \#3. Do you share your feelings and ideas spontaneously?

Question \#4. Do you seek out and accept help from other family members?

Question \#5. Are you willing to share your views of other family members with them as well as ask them for their views of yourself? No means is provided by which to separate the two concepts posed by each question or to react to them individually. As a result, it is questionable whether the responses made to these questions reflect an equal rating of both concepts incorporated in the question, a response to one or the other, or some average of the two. A clearer understanding of these three questions could be attained if each one were divided into two independent questions.

Additional inaccuracies may arise in the interpretation of these three questions as a result of some confusing and ambiguous terms. The term "spontaneously," for example, is used in question \#3 in conjunction with the sharing of feelings and ideas. However, no indication is made as to whether this is a negative or positive concept within the dynamics of any given family. The question structure leaves this determination entirely up to the respondents without allowing them to explain their interpretation of the question. A similar problem exists with question \#5. "Sharing your views of others" may be a positive or a negative attribute within a given family. Because there is no way to control for this ambiguity within the structure of the SRS, any measure of change noted on these two questions cannot be accurately termed negative or positive. 
The term "help," as used in question \#4, is also vague. It has many possible interpretations, among them: concrete help, advice, or support. Thus it can lead to discrepancies in answers received from different individuals. Likewise, the term "other family members" in question \#4 or \#5 can refer to a range of persons within the family. It is unclear whether the respondent communicates with equal facility with the entire family or differently with various family members. Question \#4 assumes an equal response to all members of the family.

As a result of the vague nature of the questions on the SRS, although change is implied by a different response on the pre- and posttests, it is not at all clear whether the change indicated is negative or positive. Moreover, a seemingly negative change shown by a person's responses on the SRS may be a distortion of the actual growth experienced by that person following MIT. A respondent might rate himself or herself lower on the posttest than he or she did on the pretest because his or her understanding of his or her level of functioning was heightened by the MIT experience. In this way, a positive change in the individual might incorrectly be recorded as a negative change.

Finally, the SRS only allows respondents to rate themselves. No feedback is available from other family members regarding their perceptions of the respondents' view of themselves or the effectiveness of their communication skills. A series of questions calling for such perception checks from other family members would add to the accuracy and clarity of this measurement.

\section{Identifying Information Questionnaire}

Much of the identifying information in this quesionnaire was 
necessary to provide the researchers with a brief profile of the families participating in the study. However, a number of questions were vague, reducing their validity.

Question \#7, "Did the Children's Services Division provide services to your family during what you would consider a crisis?" allows the respondent a number of possible interpretations. For example, would a "no" answer to this question mean that CSD did not provide any services to the family, that what CSD provided was not considered to be of service, that CSD did not respond while the family was still in crisis, or that the problem which led the family to contact CSD was not considered to be a crisis?

Question \#8, "Have you received help from CSD in resolving the problems in your family?" could also be interpreted by the respondent in more than one way. Does a "no" response mean that CSD had not yet responded or that the response was not helpful?

Question \#10 reads, "If you answered no to question \#8, wi11 the Children's Services Division be able to help you resolve these problems in the future?" It is unclear why this question is on the questionnaire, as it appears to have no bearing on the family's experience with MIT. Question \#11, "What is the general nature of the problem(s) in your family?" could potentially provide some extremely relevant information about the family's perception of itself. However, because only one problem can be checked, the scope of the question is severely limited. Respondents may be forced to ignore significant points of family tension in an effort to pinpoint the one major family problem. This is incongruous with the pluralized word "problem(s)" in the question which acknowledges the possibility of having multiple problems. Because the 
respondent is limited to only one problem area, much valuable information about family functioning may be lost.

\section{Interview Schedule}

The IS was developed by the researchers to clarify some of the ambiguities of the SRS. There was no attempt to establish the validity or reliability of the instrument. Thus, it cannot be contended that the IS is a valid test of change in problem-solving skills in the population studied or that its results can be generalized beyond that population. It was designed in its present form for the sole purpose of expanding upon the SRS.

One improvement in the IS over the SRS was the change from a sixto a five-point scale, allowing for the addition of a neutral midpoint of "no change" or "no effect." Furthermore, it appears that scaled response intervals are equally weighted.

Questions \#6 through \#11 of the IS attempt to measure change in the problem-solving skills touched upon in the SRS. However, the reliability of this instrument in quantifying change in communication skills is questionable because no information is provided by the respondents regarding the level of family functioning prior to MIT. For example, question \#6 asks, "How well do you understand what other members of your family are saying now, as compared to before MIT?" If a response of "no change" is made to this question, it is unclear whether this means that the respondents feel that their understanding has not improved despite MIT or that they always understood what others were saying. This same problem exists for questions \#7 through \#11. Moreover, these questions were intended to explore the individual's perceptions of problem areas in family 
interactions after MIT as compared to before MIT. It is questionable whether a person's recollection of prior functioning can be relied upon as an accurate basis for comparison. In addition, like the SRS, the IS was not administered to all the families in the sample at an equal interval following their participation in MIT.

\section{CONCLUSIONS}

This pilot study suffers from numerous problems in the operationalization of its variables and in the underlying theoretical rationale of the program. In particular, methodological problems, such as the lack of randomization and of a control group, weaken the internal and external validity of the study. In addition, the instruments used are of questionable reliability and validity. These problems, while limiting the generalizability of the findings of the present study, have provided the groundwork for construction of a sound design for a future study of MIT. 


\section{CHAPTER VI}

\section{FUTURE STUDY OF MULTIPLE IMPACT THERAPY}

\section{RESEARCH PROBLEM}

The preceding critique of the present study suggests the need for considerable changes in a future evaluation of MIT. First, the research problem, "Is Multiple Impact Therapy an effective form of treatment for families?" should be stated clearly and specifically. It is possible to state and measure this problem in terms of an evaluation of MIT as a treatment modality in and of itself or in comparison with other forms of treatment, such as traditional casework services. In either case, the research hypotheses should be supported by a relevant, researched theoretical framework.

Further, in writing the hypotheses, the independent variable, MIT, and the specific dependent variables should be clearly identified and operationalized for measurement. It is important that the outcome measures chosen for evaluation and research purposes be valid in that they directly tap the information needed to test the hypotheses. For example, if a hypothesis states that following treatment by MIT fewer IPs will be returned to mental hospitals, the outcome measure would be fairly clearcut--a determination of how many IPs from control and experimental groups actually required further hospitalization. However, if a hypothesis states that a family's problem-solving skills will be increased by MIT, those problem-solving skills must be defined operationally. If 
identifiable communication skills are considered an important component of problem-solving, then instruments utilized for pre- and posttesting should measure the family's use of specific communication skills in a problem-solving situation.

\section{DESIGN AND SAMPLING PLAN}

In light of the specific problems presented by the nonexperimental design of the present descriptive study, the researchers have concluded that the optimal design for a future study of MIT is the traditional randomized control-group pretest-posttest-follow-up design. There are three main advantages to this experimental design.

First, the inclusion of a control, or "no treatment," group is an essential requirement for establishing a relationship between the dependent and independent variables (Wells, Dilkes, \& Trivelli, 1972). "No treatment" should not imply that a family would be denied services by the agency in question, but rather should be defined in terms of some uniform, minimal services the family could receive from the agency. In utilizing a control group design, the internal validity so lacking in the present study would be strengthened considerably. The occurrence of extraneous variables between pre- and posttesting sessions would be controlled, since both groups could be presumed to be affected equally.

Second, the problem of external validity evident in the present study could be controlled by random sampling methods. Randomization would enhance the generalizability of outcomes of MIT to the larger population from which the treatment and control samples are drawn. Given the goals and theoretical assumptions of MIT, that population should include family systems which are experiencing internal stress and 
requesting services, and for which family therapy could be considered to be an appropriate treatment alternative. Randomization could be achieved by assigning members of this population a chronological number at the time of agency intake, then referring to a table of random numbers for the selection of MIT subjects. The remaining families could constitute the pool from which the control families would be drawn, again, from a table of random numbers. A natural comparison group could be found among the portion of the population receiving traditional services from the agency. Such a sampling plan would control optimally for bias by statistical regression, as well as for other common sampling error.

Third, the use of a follow-up measurement would provide researchers with information regarding the long- versus short-term effects of MIT. For example, if MIT has only a short-term influence upon a family's communication skills, such that it tends to disappear over time, the follow-up measurement will pick up that trend (Wells \& Dezen, 1978).

\section{DATA GATHERING METHODS AND INSTRUMENTS}

While the establishment of internal and external validity is essential to the credibility of an evaluative study, future research on the outcome of MIT could be further strengthened by improving upon the data gathering of the present study. Controlled administration of MIT, along with uniform data collection, are important methodological prerequisites (Gurman \& Kniskern, 1978). Ideally, all families should be routinely pretested within one day following their request for services. The treatment group should then receive MIT within a uniform length of time; for example, two days following the pretest. Posttesting should, similarly, be uniform. A time lapse of ninety days between pre- and 
posttesting should prove to be both adequate to allow for effective change and lengthy enough to minimize bias from possible testing effects. Follow-up testing with the same instrument should occur approximately one year after the pretest date.

Instruments used for pre-, post-, and follow-up testing should allow for both positive and negative change and should not be limited to determining change in the IP alone (Wells \& Dezen, 1978). Further, measurements of the experimental and control groups should be objective and/or uncontaminated, insuring reliability. These requirements imply that those who administer the tests must be well trained in the use of the particular measures chosen, and sufficiently removed from outcome interests to avoid bias.

It is possible to categorize measurement techniques into either self-report methods or observational methods (Cromwe11, 01son, \& Fournier, 1976). Self-report methods are those in which clients are asked to fill out written tests or are asked to verbally answer standardized questions. Observational techniques are those that include actual observation and coding of family behavioral interactions rather than the clients' perceptions of behavior. Ideally, a research design would include the use of measurement instruments of both the self-report and observational types. In this way, comparisons can be made between client responses and therapist observations as well as between perceptions and actual behaviors.

\section{Self-Report Methods}

The self-report methods can be broken down into two categories.

1. Intrapersonal - The traditional approach to family assessment 
has been to rely on testing each member of the family with conventional personality measurements (Bodin, 1968). These tests are of two types, nonprojective and projective. The nonprojective instruments measure personality variables by asking an individual to respond to forced-choice items under standardized conditions. By far the most widely used test in this category is the Minnesota Multiphasic Personality Inventory (MMPI) (Buros, Vol. 1, 1978).* Other widely used tests include the TaylorJohnson Temperamental Analysis (T-JTA) and the Edward Person Preference Schedule (EPPS) (Buros, Vol. 1, 1978). Projective personality tests require a trained test administrator to be present. The tester asks each individual to respond to ambiguous stimuli so that unconscious motivations, conflicts, and needs can be uncovered. In these tests, interpretations are subjective. Popular projective instruments include the Rorschach (ROR) and Thematic Apperception Test (TAT) (Buros, Vol. 1, 1978), and the Family Interaction Report (FIR) (Mitchell \& Sherman, 1973).

2. Interpersonal - These self-report tests are designed to measure marital and family relationships, as well as those of parent and child. In these tests, family members are asked to report on interpersonal behaviors rather than intrapsychic ones. Within the interpersonal category are those tests which measure perceived interaction and those designed to measure inferred interaction. Perceived interaction instruments tap the individual's perception of what is going on in family life and are not interpreted as actual measures of interaction. Examples of

*The test listings in Buros (Vol. 1 \& 2, 1978) include information as to where the printed tests may be obtained (publisher's address), citations of articles reporting actual use of the tests, and critical comments. 
tests in this category are the Interpersonal Checklist (ICL), ParentAdolescent Communication Inventory (PACI), and Interpersonal Perception Method (IMP) (Buros, 1974); Marital Communications Inventory (MCI) and Interpersonal Communication Inventory (ICI) (Buros, Vol. 1, 1978). In the inferred interaction category, tests rely on the subjective interpretations of the therapist, based on experience and expertise, of selfreports by individuals or pairs of individuals of interpersonal situations. This type of evaluation is very important "because often couples and families are unaware of their true feelings and behaviors and are unable to report them objectively" (Cromwell et al., 1976). Examples of inferred interaction tests include the Family Relations Test (FRT) (Buros, Vol. 1, 1978); Family Relations Indicator (FRI), Family Attitudes (TFA) (Buros, 1976); and the Family Index of Tension (FIOT) (Wells \& Rabiner, 1973).**

\section{Observational Methods}

Many authors emphasize the importance of using a technique of behavioral observation in studying families either for the purposes of evaluating treatment methods or for building family theory. Riskin and Faunce (1972) state, "The element of observation is a necessity" (p. 377), while Haley (1964) considers, "The ideal data in family research . . [is] a recording of observable events which are accurately measurable in some way so that comparisons and contrasts can be made" (p. 44). Levinger (1963) suggests that the advantages of behavioral categories, refer to Cromwe11, 01son, and Fournier, 1976, pp. 517-562. 
observation supplement those of the more introspective, subjective methods. Therefore, an ideal study of MIT would include a measurement of family behavior through the use of an observational technique.

Several criteria can be useful to the researchers in choosing a method of behavioral observation. First, the method should have content validity (Cromwell et al., 1976). Riskin and Faunce (1972) note that this criterion bases the choice on the researcher's interests and purposes, hypotheses and variables. Thus, it is important that all of these be defined prior to the selection of a technique of observational measurement.

Two important criteria, relevance and standardization, are often viewed as competing in the design of observational methods (Drechsler \& Shapiro, 1963; Haley, 1964; Levinger, 1963; Rabkin, 1965). Relevance means that the observational situation is either a natural one, such as in the family's home (0'Rourke, 1963), or a laboratory situation conceptually similar to a naturally occurring one (Strauss, 1970). Standardization, on the other hand, means that observational data from different families can be compared (Cromwell et al., 1976). Because these criteria are usually considered in the context of the construction of the observational situation, in the sense that the situation may be either natural or standardized, but not both, the possibility of a method combining relevance and standardization seems small.

One way to carry out observations of families in natural situations, the results of which can be compared, is through the use of precoded categories for recording observational data. Using this approach, the researcher determines beforehand the relevant behavioral categories, and the observer then records the number of occurrences of 
each behavior represented (Lytton, 1971). Using the same coding system makes it possible to compare family behavior across families and across situations.

Most observational categories are based on such abstract concepts as "dominance," "fragmentation," or "acknowledgment," whose operational definitions are idiosyncratic, requiring that the coder interpret the behavior observed (Lytton, 1971; Riskin \& Faunce, 1972). Lytton emphasizes the importance of rigorous definitions of the behaviors included in the categories, so as to avoid coder bias and interpretation. Haley (1964) states that "there should be no guesswork or inference in the data, although what the data 'means' must involve inference" (p. 44). Thus, a fourth criterion for an observational method is that it use coding categories which require little or no inference on the part of the observer.

Finally, observational methods should have internal consistency reliability, inter-rater reliability, and concurrent and predictive validity (Cromwell et al., 1976). Inter-rater reliability requires that raters be highly trained in the use of the observational method, that they be frequently monitored for reliability in observations of varying complexity, and that they be recalibrated frequently using standard video tapes so that their use of the observational system remains close to the standard one (Reid, 1978). While other types of reliability are occasionally documented in the literature, Riskin and Faunce (1972) state that there is little standardization in methods of reporting reliability and that validity is infrequently reported in the literature. Thus, comparing observational systems on the basis of their reliability and validity is presently difficult to do but will hopefully become more 
possible as the systems grow more sophisticated (Riskin \& Faunce, 1972).

An ideal family observational method would be based on the theoretical underpinnings of the research study; would measure relevant family behavior, either in a home situation or in a structured situation that produces conditions similar to natural ones; would measure data in precoded categories so that findings can be compared across families and across situations; and would be both reliable and valid. Adequate observational methods, listed below, will fulfill most of these criteria.

Haley (1964) devised an observational system that records the order in which family members speak, leading to a frequency count of which person follows another in speaking. The theory behind this system, documented through the use of the system, is that each family has a distinct pattern of interaction which varies from a random ordering of members' speeches, and that dysfunctional families will show a more limited pattern of responses than healthy families. Beginning efforts have been made to use this system to evaluate family therapy (Haley, 1964).

The use of pre-coded categories is demonstrated in the observational system developed by Riskin and Faunce (1970). Categories include: clarity, topic continuity, commitment, agreement and disagreement, affective intensity, quality of relationship, who speaks to whom, and interruptions. A transcript of some segments of a five-minute portion of a semi-structured interview is scored for these categories.

Researchers at the Oregon Social Learning Center have developed a 29-category system in which behavioral and environmental events are continuously coded in a home observation (Patterson, Ray, Shaw, \& Cobb, 1969). Designed to describe aggressive behaviors together with their 
antecedents and consequences, about half the code describes such events, while the other half describes pro-social behaviors. Examples of categories are: indulgence, negativism, tease, and approval.

A second home observation system for collecting behavioral interaction data on family members is the Family Observation Record (Wilcox, Goocher, \& Grove, 1978). Its coding categories contain information ranging from appropriate social interactions and maintaining family normative behaviors to responsiveness to request and the functional utilization of child management techniques.

Finally, "it is possible to devise a simple, efficient observational system which has sufficiently solid psychometric characteristics to provide useful data on outcome effectiveness (at least on a day-today observable level)" (Reid, 1978, p. 43). This approach may appeal to researchers who find none of the above-described observational systems to be conceptualiy related to their hypotheses. Reid provides a guide for constructing such an observational system.

Based on the considerations outlined in this chapter, a future study of MIT should adhere to the following criteria. The research hypothesis should be clearly stated, well defined, and could best be tested using a randomized control-group pretest-posttest-follow-up design. Administration of MIT, along with pre-, post-, and follow-up data collection should be uniform and controlled. At least two instruments for measurement of outcome should be employed. Ideally, one should be a self-report method, with the other utilizing observation of families. Instruments should be administered by well-trained, unbiased researchers. These requirements would allow for maximum validity and reliability at a11 points in the research process. 


\section{BIBLIOGRAPHY}

Ackerman, N. W. The psychodynamics of family life. New York: Basic Books, 1958.

Ackerman, N. W. A dynamic framework for the clinical approach to family conflict. In N.W. Ackerman, F. Beatman, \& S. Sherman (Eds.), Exploring the base for family therapy. New York: Family Service Association, 1961.

Ackerman, N. W. The future of family psychotherapy. In N. W. Ackerman, F. Beatman, \& S. Sherman (Eds.), Expanding theory and practice in family therapy. New York: Family Service Association, 1967.

Addario, D., \& Rodgers, T. A. Some techniques for the initial interview in couples therapy. Hospital and Community Psychiatry, 1974, 25, 799-800.

Alevizos, P. N., \& Liberman, R. P. Behavioral approaches to family crisis intervention. In H. S. Parad, H. L. P. Resnik, \& L. G. Parad (Eds.), Emergency and disaster management. Bowie, Md: Charles Press, 1976.

Anderson, P. S., Dogoloff, M. L., Roy, R. L., Swarts, G., Howard, B., \& Godfrey, J. A. Family crisis intervention program: Clark County, Washington. Washington, D.C.: U.S. Department of Justice, 1979.

Andolfi, M. Family therapy: An interactional approach. New York: Plenum, 1979.

Anthony, $W$. The relationship between human relation skills and an index of psychological adjustment. Journal of Counseling Psychology, $1973,20,489-490$.

Aponte, H. J. Underorganization in the poor family. In P. Guerin, Jr. (Ed.), Family therapy: Theory and practice. New York: Gardner, 1976.

Armsby, R. E. The adolescent crisis team: An experiment in community crisis intervention. Proceedings of the 79th Annual Convention of the American Psychological Association, 1971, 6 , 735-736.

Atteneave, C. L. Therapy in tribal settings and urban network intervention. Family Process, $1969, \underline{8}(2), 192-210$. 
Baldwin, B. A paradigm for the classification of emotional crises: Implications for crisis intervention. American Journal of Orthopsychiatry, 1978, 48(3), 538-551.

Baron, R. Probation officers: Family crisis counseling and juvenile diversion (Parts $1 \& 2$ ). Dissertation Abstracts International, $1978,38(7-B), 3462-3463$.

Bart, M. R., \& Balyeat, R. A new system for improving the care of neglected and abused children. Child Welfare, 1974, 53(3), 167-179.

Bateson, G. Communication theories in relation to the etiology of the neuroses. Symposium on the Etiology of the Neuroses. New York: Society of Medical Psychoanalysis, 1962.

Bateson, G., Jackson, D. D., Haley, J., \& Weakland, J. H. Toward a theory of schizophrenia. Behavioral Science, 1956, $1,251-264$.

Beatman, F. L. Intergenerational aspects of family therapy. In N. W. Ackerman, F. L. Beatman, \& S. N. Sherman (Eds.), Expanding theory and practice in family therapy. New York: Family Service Association, 1967.

Be11, J. Family therapy. New York: Aronson, 1975.

Berlin, I. Crisis intervention and short-term therapy: An approach in a child psychiatric unit. In G. Morrison (Ed.), Emergencies in child psychiatry. Springfield, I11.: Thomas, 1975.

Biddle, B. J., \& Thomas, E. J. (Eds.). Role theory: Concepts and research. New York: Wiley, 1966.

Bishof, L. J. Interpreting personality theories. New York: Harper and Row, 1964.

Bodin, A. M. Conjoint family assessment: An evolving field. In P. McReynolds (Ed.), Advances in psychological assessiment (Vol. 1). Palo Alto, Calif.: Science and Behavior Books, 1968.

Boyd, E., Clark, J., Kempler, H., Johannet, P., Leonard, B., \& McPherson, P. Teaching interpersonal communication to troubled families. Family Process, $1974, \underline{13}(3), 317-336$.

Breslow, D. B., \& Hron, B. G. Time-extended family interviewing. Family Process, $1977,16(1), 97-103$.

Brody, E. M., \& Spark, G. M. Institutionalization of the aged: A family crisis. Family Process, $1966, \underline{5}(1), 76-90$.

Buros, 0. K. (Ed.). Tests in print. Highland Park, N.J.: Gryphon Press, 1974. 
Buros, 0. K. (Ed.). The eighth mental measurements yearbook (Vol. 1-2). Highland Park, N.J.: Gryphon Press, 1978.

Carkhuff, R. Helping and human relations: Practice and research (Vol. 2). New York: Holt, Rinehart, Winston, 1969.

Carpenter, W. T., Sacks, M. H., Strauss, J. S., Bartko, J. J., \& Rayner, J. Evaluating signs and symptoms: Comparison of structured interviews and clinical approaches. British Journal of Psychiatry, $1976,128,397-403$.

Clausen, J. A. Sociology and psychiatry. In A. E. Friedman, H. I. Kaplan, \& B. J. Sadock (Eds.), Comprehensive textbook of psychiatry (Vol. 1). Baltimore: Williams and Wilkins, 1976.

Cohen, P., Dizenhuz, I. M., \& Winget, C. Family adaptation to terminal illness and death of a parent. Social Casework, 1977, 58(4), 223-228.

Counts, R. M. Family crisis and the impulsive adolescent. Archives of General Psychiatry, 1967, 17(1), 64-71.

Cromwell, R., 0lson, D., \& Fournier, D. Diagnosis and evaluation in marital and family counseling. In D. 01son (Ed.), Treating relationships. Lake Mills, Iowa: Graphic, 1976.

Cronin-Stubbs, D. Family crisis intervention: A study. Journal of psychiatric nursing and mental health services, $1978,16(1), 36-44$.

Cronkhite, G. Communication and awareness. Menlo Park, Calif.: Cummings, 1976 .

Darbonne, A. Crisis: A review of theory, practice and research. International Journal of Psychiatry, 1968, 6(5), 371-378.

Drechsler, R. J., \& Shapiro, M. I. Two methods of analysis of family diagnostic data. Family Process, 1963, $2(2), 367-379$.

Egan. G. The skilled helper. Monterey, Calif.: Brooks/Cole, 1975.

Eisenstedt, S. N., Wintraub, D., \& Toren, N. Analysis of progresses of role change. Jerusalem: Israel University Press, 1967.

Elbert, S., Rosman, B., Minuchin, S., \& Guerney, B. A method for the clinical study of family interaction. American Journal of Orthopsychiatry, 1964, 34(5), 885-894.

Ewalt, P. L. The crisis treatment approach in a child guidance clinic. Social Casework, 1973, 54(7), 406-411. 
Ferreira, A. J., Winter, W. D., \& Poindexter, E. J. Some interactional variables in normal and abnormal families. Family Process, 1966, $\underline{5}(1), 60-75$.

Flomenhaft, K., Kaplan, D. M., \& Langsley, D. G. Avoiding psychiatric hospitalization. Social Work, $1969,14(4), 38-45$.

Fong, J. Y., Schneider, M., \& Walls-Cooke, P. Multiple family group therapy with a tri-therapist team. Nursing Clinics of North America, 1978, 13(4), 685-699.

Forcese, D. P., \& Richer, S. Social research methods. Englewood Cliffs, N.J.: Prentice-Hal1, 1973.

Framo, J. L. Symptoms from a family transactional viewpoint. In C. J. Sager \& H. S. Kaplan (Eds.). Progress in group and family therapy. New York: Brunner/Maze1, 1972.

Frank, I., \& Frank, R. The management of adolescent crises in family practice. Adolescence, $1975, \underline{10}(37), 25-28$.

Gilbert, S. Self-disclosure, intimacy and communication in families. Family Coordinator, $1976, \underline{25}(3), 221-231$.

Glasser, P. H. Introduction. In P. H. Glasser \& L. N. Glasser (Eds.), Families in crisis. New York: Harper and Row, 1970.

Golan, N. Short-term crisis intervention: An approach to serving children and their families. Child Welfare, 1971, 50(2), 101-107.

Golan, N. Crisis theory in families. In F. J. Turner (Ed.), Social work treatment. New York: Free Press, 1974.

Goldstein, H. Providing services to children in their own homes: An approach that can reduce foster placement. Children Today, 1973, 2(4), 2-7.

Goldstein, J., Freud, A., \& Solnit, A. J. Beyond the best interests of the child. New York: Free Press, $197 \overline{3 .}$

Goodrich, D. W., \& Boomer, D. S. Experimental assessment of modes of conflict resolution. Family Process, 1963, $2(1), 15-27$.

Goolishian, H. A. A brief psychotherapy program for disturbed adolescents. American Journal of Orthopsychiatry, 1962, 32, 142-148.

Grando, R., \& Ginsburg, B. Communication in the father-son relationship: The parent-adolescent relationship development program. Family Coordinator, 1976, 25(4), 465.

Gray, W. Multiple therapist therapy: A preliminary report. General Systems, 1973, 18, 175-176. 
Green, A., \& Marlatt, G. A. Effects of instructions and modeling upon affective and descriptive verbalization. Journal of Abnormal Psychology, 1972, 80 (2), 189-196.

Greenberg, G. S. The family interactional perspective: A study and examination of the work of Don D. Jackson. Family Process, 1977, $16(4), 385-412$.

Group for the Advancement of Psychiatry. Treatment of families in conflict: The clinical study of family process. New York: Science House, 1970.

Gurman, A. S., \& Kniskern, D. Technolatry, methodolatry, and the results of family therapy. Family Process, 1978, 17(3), 275-281.

Haley, J. Family experiments: A new type of experimentation. Family Process, $1962,1(2), 265-293$.

Haley, J. Research on family patterns: An instrument measurement. Family Process, $1964, \underline{3}(1), 41-65$.

Haley, J. Problem solving therapy. New York: Harper and Row, 1976.

Handel, G. (Ed.). The psychosocial interior of the family. Chicago: Aldine, 1967.

Hansen, C. C. An extended home visit with conjoint family therapy. Family Process, 1968, ㄱ(1), 67-87.

Henry, A. F. Family role structure and self blame. In N. W. Bell \& E. F. Vogel (Eds.), A modern introduction to the family. New York: Free Press, 1960.

Higgins, W. H., Ivey, A., \& Uhlemann, M. R. Media-therapy: A programmed approach to teaching behavior skills. Journal of Counseling Psychology, 1970, 17(1), 20-26.

Hill, R. Generic features of families under stress. Social Casework, 1958, 39(2-3), 139-150. Reprinted in H. J. Parad (Ed.), Crisis intervention: Selected readings. New York: Family Service Association, 1965.

Homer, L. E. Community-based resource for runaway girls. Social Casework, $1973,54(8), 473-479$.

Hooker, C. E. Learned helplessness. Social Work, 1976, 21(3), 194-198.

Howe11s, J. G. Principles of family psychiatry. New York: Brunner/ Maze $1,1975$. 
Howes, K. Epigenesis: The natural development of family crisis leading to the hospitalization of adolescents. Family Coordinator, 1976, $25(3), 249-254$.

Ivey; A. Micro counseling: Innovations in interview training. Springfield, I17.: Thomas, 1971.

Jackson, D. D. The question of family homeostasis. Psychiatric Quarterly Supplement, $1957, \underline{31}, 79-90$.

Jackson, D. D. A study of family structures. Psychological Reports, $1963, \underline{13}(2), 422$.

Jackson, D. D., \& Weakland, J. H. Conjoint family therapy. Psychiatry, $1961, \underline{24}(2), 30-45$.

Kagle, J. D. Evaluating social work practice. Social Work, 1979, 24(4), 292-296.

Kaplan, D. Problem conception and planned intervention. In P. H. Glasser \& L. N. Glasser (Eds.), Families in crisis. New York: Harper and Row, 1970.

Kempe, C. H. A practical approach to the protection of the abused child and rehabilitation of the abusing parent. Pediatrics, 1973, $\underline{5}(4)$, 804-812.

Kinney, J. Home builders: An in-home crisis intervention program. Children Today, 1978, 근 1 , 15-17; 35.

Kinney, J., Madsen, B., Fleming, T., \& Haapala, D. Home builders: Keeping families together. Journal of Consulting and Clinical Psychology, 1977, 45 (4), 667-673.

Krider, J. W., Jr. A new program and its impact on a small agency. Social Casework, 1969, 50(9), 508-512.

Lang, J. Planned short-term treatment in a family agency. Social Casework, $1974, \underline{55}(6), 369-374$.

Langsley, D. G., Fairbairn, R. H., \& DeYoung, C. D. Adolescence and family crises. Canadian Psychiatric Association Journal, 1968, $\underline{13}(2), 125-133$.

Langsley, D. G., Flomenhaft, K., \& Machotka, P. Follow-up evaluation of family crisis therapy. American Journal of Orthopsychiatry, 1969, 39(5), 753-759.

Langsley, D. G., \& Kaplan, D. Treatment of families in crisis. New York: Grune and Stratton, 1968. 
Langsley, D. G., Pittman, F. S., Machotka, P., \& Flomenhaft, K. Family crisis therapy: Results and implications. Family Process, 1968, 7(2), 145-158.

LaVietes, R. L. Crisis intervention for ghetto children: Contraindications and alternative considerations. American Journal of Orthopsychiatry, 1974, 44(5), 720-727.

Levinger, G. Supplementary methods in family research. Family Process, $1963,2(2), 357-366$.

Lidz, T., Cornelison, A. R., Fleck, S., \& Terry, D. Schism and skew in the families of schizophrenics. In N. W. Bell \& E. F. Vogel (Eds.), A modern introduction to the family. New York: Free Press, 1960.

Lidz, T., Fleck, S., \& Cornelison, A. R. Schizophrenia and the family. New York: Internationa 1 University Press, 1965.

Littner, $N$. Some traumatic effects of separation and placement. New York: Child Welfare League, 1956.

Loveland, N. T., Wynne, L. C., \& Singer, M. T. The family Rorschach: A new method for studying family interaction. Family Process, 1963, 2(2), 187-215.

Luber, R. F., \& Wells, R. Structured, short-term multiple family therapy: An educational approach. International Journal of Group Psychotherapy, 1977, 27(1), 43-58.

Lytton, H. Observation studies of parent-child interaction: A methodological review. Child Development, 1971, 42(3), 651-684.

MacGregor, R. Multiple impact psychotherapy with families. Family Process, $1962,1(1), 15-29$.

MacGregor, R. Multiple impact therapy with families. New York: McGrawHi11, 1964.

Mackey, R. A. Crisis theory: Its development and relevance to social casework practice. Family Coordinator, 1968, 17(3), 165-173.

Matteson, R. Adolescent self-esteem, family communication, and marital satisfaction. Journal of Psychology, January 1974, 86, 35-47.

McGee, R. K. Crisis intervention in the community. Baltimore: University Park, 1974.

McMurrain, T. Intervention in human crisis. Atlanta: Humanics Press, 1975.

McPherson, S. R., Brackelmanns, W. E., \& Newman, L. E. Stages in the family therapy of adolescents. Family Process, 1974, 13(1), 77-94. 
Messer, A. A. The individual in his family: An adaptational study. Springfie 7 , I11.: Thomas, 1970.

Minuchin, S. Families and family therapy. Cambridge, Mass.: Harvard University Press, 1974.

Minuchin, S., \& Barcai, A. Therapeutically induced family crisis. In J. Masserman (Ed.), Science and psychoanalysis (Vol. 14). New York: Grune and Stratton, 1969.

Minuchin, S., Montalvo, B., Guerney, B., Rosman, B., \& Schumer, F. Families of the slums. New York: Basic Books, 1967.

Mitchel1, C. B. Family interviewing in family diagnosis. Social Casework, $1959,40(7), 381-384$.

Mitche11, C. B. Integrative therapy of the family unit. Social Casework, $1965, \underline{46}(2), 63-69$.

Mitchel1, C., \& Sherman, M. H. Themes of family complimentarity evident in individual psychological testing. The Israel Annals of Psychiatry and Related Disciplines, 1973, 11(4), 275-287.

Morris, B. Crisis intervention in a public welfare agency. Social Casework, $1968, \underline{49}(10), 612-617$.

Morrison, G. C., \& Collier, J. G. Family treatment approaches to suicidal children and adolescents. Journal of the American Academy of Child Psychiatry, 1969, $8,140-153$.

Moustakas, C. E., Sigel, I. E., \& Schalock, H. D. An objective method for the measurement and analysis of child-aduit interaction. Child Development, 1956, 27(2), 109-134.

Nelson, Z. P., \& Mowry, D. D. Contracting in crisis intervention. Community Mental Health Journal, 1976, 12(1), 37-45.

Nye, F. I., Bahr, H. M., Bahr, S. J., Carlson, J. E., Gecas, V., McLaughlin, S., \& Slocum, W. L. Role structure and analysis of the family. Beverly Hills, Calif.: Sage Publications, 1976.

0lson, K. J. An investigation of scapegoating, favoritism, and selfblame in families. Dissertation Abstracts, 1968, 29, 484A-485A.

0'Rourke, J. F. Field and laboratory: The decision making behavior of family groups in two experimental conditions. Sociometry, 1963, $26(4), 422-435$.

Parad, H. J., \& Caplan, G. A framework for studying families in crisis. Social Work, 1960, 5(3), 3-15. Reprinted in H. J. Parad (Ed.), Crisis intervention: Selected readings. New York: Family Service Association, 1965. 
Parsons, B. V. Family crisis intervention: Therapy outcome study. Dissertation Abstracts International, 1972, 32, 6657B. (No. 72-16, 047)

Parsons, T., \& Bales, R. F. Family: Socialization and interaction process. New York: Free Press, 1960.

Patrick, J. D., \& Wander, R. S. Treatment of the adolescent crisis patient. Psychotherapy: Theory, Research and Practice, 1974, 11(13), 246-250.

Patterson, G. R., Ray, R. S., Shaw, D., \& Cobb, J. A. Manual for coding family interactions (Sixth Revision). 1969. ASIS National Auxiliary Publication Service: c/o CCM Information Services, Inc., 909 Third Avenue, New York, N.Y. 10022. Document \#01234.

Paul, G. L. Strategy of outcome research in psychotherapy. Journal of Consulting Psychology, 1967, 31(2), 109-118.

Pierre, R. M., \& Drasgow, J. Teaching facilitative interpersonal functioning to psychiatric inpatients. Journal of Counseling Psychology, $1969, \underline{16}(4), 295-298$.

Pittman, F. S., DeYoung, C., Flomenhaft, K., Kaplan, D. M., \& Langsley, D. G. Crisis family therapy. In J. H. Masserman (Ed.), Current psychiatric therapies (Vol. 6). New York: Grune and Stratton, 1966.

Polak, P. Social systems intervention. Archives of General Psychiatry, $1971, \underline{25}(2), 110-117$.

Rabkin, L. Y. The patient's family: Research methods. Family Process, $1965, \underline{4}(1), 105-132$.

Rapoport, L. The state of crisis: Some theoretical considerations. Social Service Review, 1962, 36(2), 211-217.

Rapoport, L. Working with families in crisis: An exploration of preventive intervention. Social Work, $1962, \underline{7}(3), 48-56$.

Rapoport, L. Crisis oriented short-term casework. Social Service Review, 1967, 41(1), 31-42.

Rapoport, R. Normal crises, family structure and mental health. Family Process, 1963, $2(1), 68-80$.

Reid, J. B. (Ed.). A social learning approach to family intervention: Observation in home settings (Vol. 2). Eugene, Ore.: Castalia Publishing, 1978.

Reistroffer, M. The placement process. Transcript of speech presented October 18, 1972. Possibly available from author, University of Wisconsin. 
Reuben, H. L. Family crisis. American Family Physician, 1975, 11, 132136.

Reuben, H. L. Unscrambling family crises. Practical Psychology for Physicians, June 1976, 77-78.

Rhodes, S. D. A developmental approach to the life cycle of the family. Social Casework, 1977, 58(5), 301-311.

Riskin, J. Family interaction scales: A preliminary report. Archives of General Psychiatry, 1964, 11(5), 484-494.

Riskin, J., \& Faunce, E. E. Family interaction scales: Theoretical framework and method. Archives of General Psychiatry, 1970, 22(6), 504-526.

Riskin, J., \& Faunce, E. E. An evaluative review of family interaction research. Family Process, 1972, 11(4), 365-455.

Ritchie, A. Multiple impact therapy: An experiment. Social Work, 1960, $\underline{5}(3), 16-21$.

Ritchie, A., \& Serrano, A. C. Family therapy in the treatment of adolesscents with divorced parents. In R. E. Hardy \& J. C. Hull (Eds.). Therapeutic needs of the family. Springfield, I11.: Thomas, 1974.

Rosenberg, B. Planned short-term treatment in developmental crises. Social Casework, 1975, 56 (4), 195-204.

Rossiter, C. M., \& Pearce, W. B. Communicating personally. Indianapolis: Bobbs-Merri11, 1975.

Roth, F. A practice regimen for diagnosis and treatment of child abuse. Child Welfare, $1975,54(4), 268-273$.

Rueveni, U. Family network intervention: Healing families in crisis. Intel lect, 1976, 104(2375), 580-582.

Saghir, M. T. A comparison of some aspects of structured and unstructured interviews. American Journal of Psychiatry, 1971, 128(2), 180-184.

Satir, V. Conjoint family therapy. Palo Alto, Calif.: Science and Behavior Books, 1967.

Sauber, M. Review of A second chance for families: Evaluation of a program to reduce foster care by M. A. Jones, R. Neuman, \& A. W. Shyne. Child Welfare, 1976, 55(10), 727-730.

Scherz, F. H. The crisis of adolescence in family life. Social Casework, $1967, \underline{48}(4), 209-215$. 
Schulman, R. E., Shoemaker, D. J., \& Moelis, I. Laboratory measurement of parental behavior. Journal of Consulting Psychology, 1962, $\underline{26}(2), 109-114$.

Selig, A. Crisis theory and family growth. Family Coordinator, 1976, 25(3), 291-295.

Selltiz, C., Wrightsman, L. S., \& Cook, S. W. Research methods in social relations. New York: Holt, Rinehart, Winston, 1976.

Shaw, D., Fore, K., Ritchie, A., McAnulty, M., \& Nixon, G. Multiple impact therapy. American Journal of Nursing, 1977, 77(2), 246-248.

Sloman, L., \& Webster, C. Assessing the parents of the learning disabled child: A semi-structured interview procedure. Journal of Learning Disabilities, $1978, \underline{11}(2), 73-79$.

Smith, L. L. A general model of crisis intervention. Clinical Social Work Journal, $1976, \underline{4}(3), 162-171$.

Smith, L. L. A review of crisis intervention theory. Social Casework, $1978, \underline{59}(7), 396-405$.

Smith, L. L. Crisis intervention in practice. Social Casework, 1979, $\underline{60}(2), 81-88$.

Sojit, C. M. Dyadic interaction in a double-bind situation. Family Process, $1969,8(2), 235-259$.

Speck, R. V., \& Rueveni, U. Treating the family in the time of crisis. In J. H. Masserman (Ed.), Current psychiatric therapies (Vol. 17). New York: Grune and Stratton, 1977.

Spiegel, J. P. The resolution of role conflict within the family. In N. W. Bell \& E. F. Vogel (Eds.), A modern introduction to the family. New York: Free Press, 1960.

Strauss, M. A. Methodology of laboratory experimental study of families in three societies. In R. Hill \& R. König (Eds.), Families in East and West. Paris: Mouton, 1970.

Strean, H. (Ed.). Social casework: Theories in action. Metuchen, N.J.: Scarecrow Press, 1971.

Strean, H. S. Role theory, role models, and casework: Review of the literature and practice applications. Social Work, 1967, 12(2), 77-88.

Strickler, M. Applying crisis theory in a community clinic. Social Casework, 1965, 46 (3), 150-154. 
Strickler, M., \& Bonnefil, M. Crisis intervention and social casework: Similarities and differences in problem-solving. Clinical Social Work Journal, $1974,2(1), 36-44$.

Stuart, M. R., \& Machey, K. J. Defining the differences between crisis intervention and short-term therapy. Hospital and Community Psychiatry, 1977, 28(7), 527-529.

Sullivan, D., Bodin, A. M., \& Everstine, L. Emergency psychology: A mobile service for police crisis calls. Family Process, 1977, $\underline{16}(3), 281-292$.

Treppa, J. A. Interpersonal dynamics related to the utilization of multiple therapy. American Journal of Psychotherapy, 1974, 28(1), 71-83.

Tyler, E. A., Truumaa, A., \& Henshaw, P. Family group intake by a child guidance clinic team. Archives of General Psychiatry, 1962, $\underline{6}(3)$, 214-218.

Vidich, A. J. Methodological problems in the observation of husband-wife interaction. Marriage and Family Living, 1956, 18, 234-239.

Vitalo, R. Teaching improved interpersonal functioning as a preferred mode of treatment. Journal of Clinical Psychology, 1971, 27(2), 166-171.

Vogel, E. F., \& Bell, N. W. The emotionally disturbed child as the family scapegoat. In N. W. Bell \& E. F. Vogel (Eds.), A modern introduction to the family. New York: Free Press, 1960.

Wahlroos, S. Family communication. New York: Macmillan, 1974.

Wallace, M. A., \& Schreiber, F. B. Crisis intervention training for police officers: A practical program for local police departments. Journal of Psychiatric Nursing and Mental Health Services, 1977, 15(2), 25-29.

Watzlawick, P. A structured family interview. Family Process, 1966, $\underline{5}(2), 256-271$.

Weakland, J. Family therapy as a research arena. Family Process, 1962, $\underline{1}(1), 63-68$.

Wells, C. F., \& Rabiner, E. L. The conjoint family diagnostic interview and the family index of tension. Family Process, 1973, 12(2), 127-144.

Wells, R. A., \& Dezen, A. E. Ideologies, idols (and graven images?): Rejoinder to Gurman and Kniskern. Family Process, 1978, 17(3), 283-287. 
Wells, R. A., \& Dezen, A. E. The results of family therapy revisited: The nonbehavioral methods. Family Process, 1978, 17(3), 251-273.

Wells, R. A., Dilkes, T. C., \& Trivelli, N. The results of family therapy: A critical review of the literature. Family Process, 1972, 11(2), 189-207.

Wilcox, J. K., Goocher, B. E., \& Grove, D. N. The family observation record. Edgefield Lodge, Troutdale, Ore., 1978.

Williams, A. R. The initial conjoint marital interview: One procedure. Family Coordinator, $1974, \underline{23}(4), 391-395$.

Willner, M., Perry, H., \& Rhem, T. N. Project treat: A new approach to the severely disabled child. Child Welfare, 1972, 51(7), 460-464.

Zelditch, M. Role differentiation in the nuclear family. In N. W. Bell \& E. F. Vogel (Eds.), A modern introduction to the family. New York: Free Press, 1960. 
APPENDIX 
APPENDIX A

TABLE 1

Self-Rating Scale: Total Family Mean of Change Across Items

\begin{tabular}{lcccc}
\hline Family & $\begin{array}{c}\text { Total } \bar{X} \\
\text { Before }\end{array}$ & $\begin{array}{c}\text { Total } \bar{X} \\
\text { After }\end{array}$ & $\bar{X}$ Difference & $p^{\mathrm{a}}$ \\
\hline Family \#1 & 25.50 & 21.00 & -4.50 & 0.219 \\
\hline Family \#2 & 18.25 & 20.00 & 1.75 & 0.035 \\
\hline Family \#3 & 16.83 & 19.83 & 3.00 & 0.060 \\
\hline Family \#4 & 16.80 & 18.20 & 1.40 & 0.052 \\
\hline Family \#5 & 17.67 & 17.33 & -0.33 & 0.667 \\
\hline Family \#6 & 17.00 & 15.33 & -1.67 & 0.525 \\
\hline Family \#7 & 13.80 & 18.20 & 4.40 & 0.083 \\
\hline Family \#8 & 11.00 & 13.00 & 2.00 & 0.201 \\
\hline Family \#9 & 18.50 & 18.67 & 0.17 & 0.944 \\
\hline Family \#10 & 18.00 & 19.67 & 1.67 & 0.630 \\
\hline Family \#11 & 13.00 & 11.40 & -1.60 & 0.056 \\
\hline
\end{tabular}

${ }^{a}$ Two tailed $\underline{t}$-test for significance of difference between means. 
Washington Branch

326 N.E. LINCOLN STREET, P.O. BOX 315, HILLSBORO, OREGON 97123 PHONE 648-8951

Dear

As part of our survey of families receiving services from the Children's Services Division, graduate students from the School of Social Work at Portland State University are conducting brief interviews with families regarding the services they have received. It is hoped that the results of this study will help other families requesting such services, and your participation would be greatly appreciated.

If your family agrees to take part in this brief interview, it will be conducted at your convenience in your home. All information will be held in confidence, and your name will never be used in conjunction with the study. Your participation will in no way jeopardize your present or future relationship with CSD. In order to protect the rights of all persons taking part in this study, we need your permission in writing to be interviewed. All family members over seven years of age must give their consent. All information and data will be aggregated to protect all families participating. If you have any questions about the survey, please feel free to call Mr. Bill Showell at 648-8951.

A stamped, addressed envelope is enclosed for your convenience. Thank you for your cooperation in this effort. 


\section{APPENDIX C}

IDENTIFYING INFORMATION QUESTIONNAIRE

\section{Introduction:}

You were selected to participate in this survey because you have received services recently from Washington County Children's Services Division. The purpose of this survey is to obtain information regarding problems experienced by families and the services provided by the Children's Services Division.

Your assistance and openness in providing complete information will greatly assist the research effort. After a brief questionnaire is completed, each family member will be asked to complete a self-rating scale.

Who completed the questionnaire for the family?

a parent

a child

more than one family member 
APPENDIX C

\section{IDENTIFYING INFORMATION QUESTIONNAIRE}

\section{(QUESTIONNAIRE TO BE COMPLETED BY FAMILY MEMBERS)}

Please answer the following questions as they describe your present family composition. Reference to "first contact with the Children's Services Division" is to that contact made during March 1, 197 to September 1, 197 .

1. How many family members are presently living together in the family place of residence?

Please complete the following chart for each family member. Do not identify by name but as mother, father, daughter, etc.

\begin{tabular}{|l|l|l|l|l|l|}
\hline $\begin{array}{l}\text { Family } \\
\text { member }\end{array}$ & Age & Sex & \multicolumn{2}{|c|}{$\begin{array}{c}\text { Level of } \\
\text { Education }\end{array}$} & \multicolumn{2}{|c|}{$\begin{array}{c}\text { Employed } \\
\text { yes no }\end{array}$} \\
\hline & & & & & \\
\hline & & & & & \\
\hline & & & & & \\
\hline & & & & & \\
\hline & & & & & \\
\hline
\end{tabular}

2. Has any family member been removed or left your family to live elsewhere since your first contact with the Children's Services Division intake worker?

yes

no

3. Has any member returned to live with your family since your first contact with the Children's Services Division intake worker?

yes

no 


\section{APPENDIX C}

4. If you have answered yes to either item \#2 or \#3, please complete the following chart.

\begin{tabular}{|l|l|l|l|l|l|l|}
\hline $\begin{array}{l}\text { Family } \\
\text { member }\end{array}$ & Age & Sex & $\begin{array}{c}\text { Now in } \\
\text { home }\end{array}$ & $\begin{array}{c}\text { Returned } \\
\text { from }\end{array}$ & $\begin{array}{l}\text { Not out } \\
\text { of home }\end{array}$ & Whereabouts \\
\hline & & & & & & \\
\hline & & & & & & \\
\hline & & & & & & \\
\hline
\end{tabular}

5. What is the total yearly income of all family members?

$$
\begin{array}{ll}
\text { below } \$ 10,000 & \$ 20,000 \text { to } \$ 29,999 \\
\$ 10,000 \text { to } \$ 19,999 & \text { above } \$ 30,000
\end{array}
$$

6. Which of the following were the cause of your family receiving services from the Children's Services Division? Check all that apply.

$$
\begin{aligned}
& \text { - divorce } \quad \text { - runaway } \quad \text { school problems - financial problems } \\
& \text { - death - drugs/alcohol Esuicide } \\
& \text { - arguments - - truancy - medical problems } \\
& \text { - obuse (explain) - family conflict - physical violence }
\end{aligned}
$$

7. Did the Children's Services Division provide services to your family during what you would consider a crisis?

$$
\text { yes _ no don't know }
$$

8. Have you received help from the Children's Services Division in resolving the problems in your family?

yes __ no

9. If you answered yes to question \#8, how have the problems been resolved? out-of-home placement of a family member

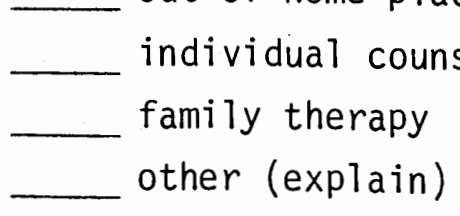




\section{APPENDIX C}

10. If you answered no to question \#8, will the Children's Services Division be able to help you resolve these problems in the future?

$$
\text { yes }
$$

no

11. What is the general nature of the problem(s) in your family? (check only one)

financial delinquency family communication legal marital other (explain) 


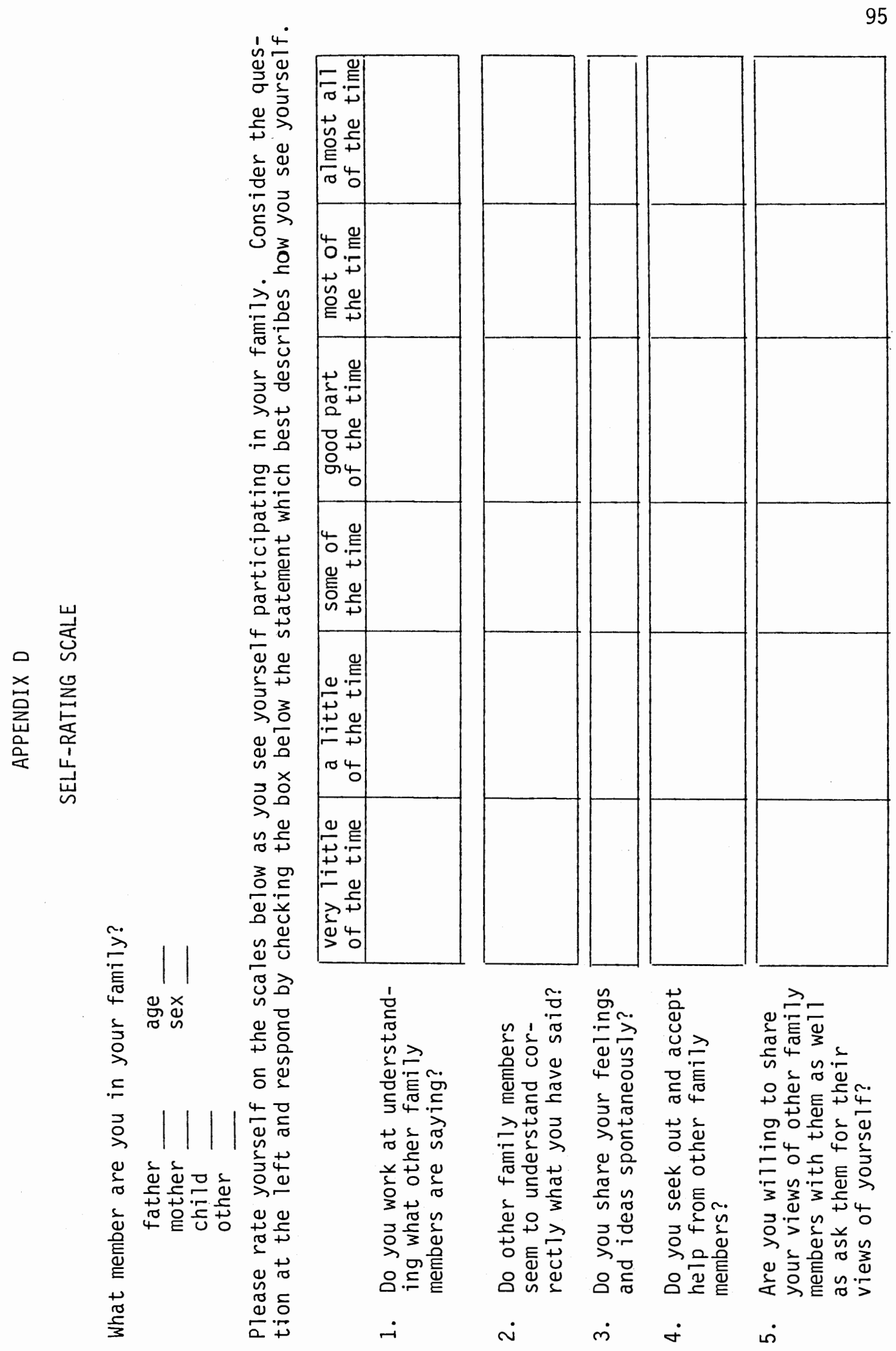




\section{APPENDIX E}

\section{INTERVIEW SCHEDULE}

Interviewer

Date of Interview Case Number

\section{INTERVIEW SCHEDULE: EVALUATION OF MULTIPLE IMPACT THERAPY}

Please rate the following statements according to how you feel your family situation has changed since Multiple Impact Therapy.

1. The way we get along since the multiple impact therapy is

$\begin{array}{lllll}1 & 2 & 3 & 4 & 5 \\ \text { much change } & \text { some change } & \text { no } & \text { some change } & \text { much change } \\ \text { for the } & \text { for the } & \text { change } & \text { for the } & \text { for the } \\ \text { worse } & \text { worse } & & \text { better } & \text { better }\end{array}$

2. I found the communication skills we learned

$\begin{array}{lllll}1 & 2 & 3 & 4 & 5 \\ \text { not at all } & \text { not very } & \text { to have } & \text { somewhat } & \text { very } \\ \text { useful } & \text { useful } & \text { no effect } & \text { useful } & \text { useful }\end{array}$

3. In general, the problems which led us to call CSD have shown

$\begin{array}{lllll}1 & 2 & 3 & 4 & 5 \\ \text { much change } & \text { some change } & \text { no } & \text { some change } & \text { much change } \\ \text { for the } & \text { for the } & \text { change } & \begin{array}{l}\text { for the } \\ \text { better }\end{array} \\ \text { worse } & \text { worse } & & \text { better }\end{array}$

4. Which of the following statements best expresses how you think the MIT experience affected your family?

1. As a result of MIT, our problems got much worse.

2. As a result of MIT, our problems got somewhat worse.

3. The MIT had no effect on our problems.

4. As a result of MIT, our problems got somewhat better.

5. As a result of MIT, our problems got much better.

5. How do you feel about your experience with MIT? 


\section{APPENDIX E}

6. How well do you understand what other members of your family are saying now, as compared to before MIT?

$\begin{array}{lllll}1 & 2 & 3 & 4 & 5 \\ \text { much } & \text { somewhat } & \text { no } & \text { somewhat } & \text { much } \\ \text { worse } & \text { worse } & \text { change } & \text { better } & \text { better }\end{array}$

7. Do you listen more or less to what other members of your family are saying now, as compared to before MIT?

$\begin{array}{lllll}1 & 2 & 3 & 4 & 5 \\ \text { much } & \text { somewhat } & \text { no } & \text { somewhat } & \text { much } \\ \text { less } & \text { less } & \text { change } & \text { more } & \text { more }\end{array}$

8. Do you find it easier or harder to express your feelings to family members now, as compared to before MIT?

$\begin{array}{lllll}1 & 2 & 3 & 4 & 5 \\ \text { much } & \text { somewhat } & \text { no } & \text { somewhat } & \text { much } \\ \text { harder } & \text { harder } & \text { change } & \text { easier } & \text { easier }\end{array}$

9. Rate your willingness to go to someone in your family for help with a problem now, as compared to before MIT.

$\begin{array}{lllll}1 & 2 & 3 & 4 & 5 \\ \text { much less } & \text { somewhat } & \text { no } & \text { somewhat } & \text { much } \\ \text { willing } & \text { less } & \text { change } & \text { more } & \text { more } \\ & \text { willing } & & \text { willing } & \text { willing }\end{array}$

10. Rate your willingness to accept help with a problem from family members now, as compared to before MIT.

$\begin{array}{lllll}1 & 2 & 3 & 4 & 5 \\ \text { much less } & \text { somewhat } & \text { no } & \text { somewhat } & \text { much } \\ \text { willing } & \text { less } & \text { change } & \text { more } & \text { more } \\ & \text { willing } & & \text { willing } & \text { willing }\end{array}$

11. Rate your willingness to offer help with a problem to other family members now, as compared to before MIT?

$\begin{array}{lllll}1 & 2 & 3 & 4 & 5 \\ \text { much less } & \text { somewhat } & \text { no } & \text { somewhat } & \text { much } \\ \text { willing } & \text { less } & \text { change } & \text { more } & \text { more } \\ & \text { willing } & & \text { willing } & \text { willing }\end{array}$


APPENDIX E

(Page 3)

INTERVIEW SCHEDULE

Case Number

12. When you first contacted CSD you identified the following as the major problems concerning your family:

Please rate each problem according to how it has changed for you since MIT.

1

much change

for the

worse

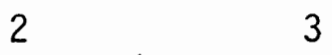

some change

for the

worse
3

change

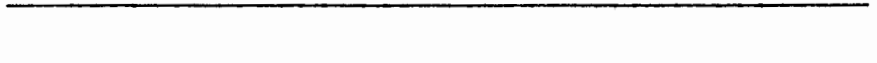

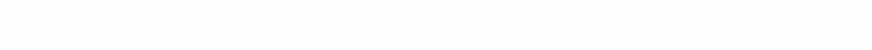
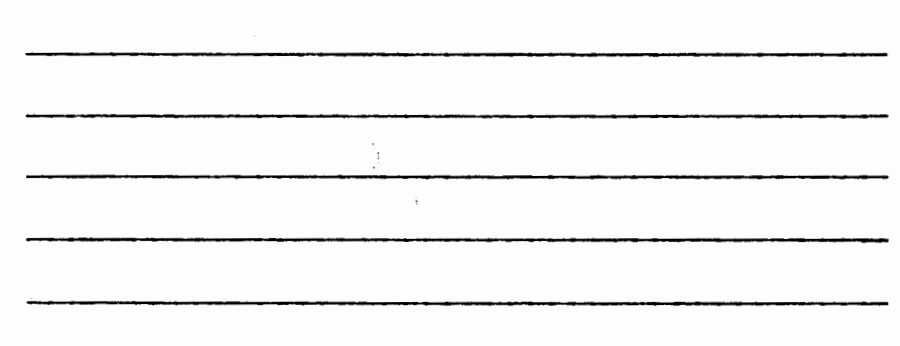

5 much change for the better

$\begin{array}{lllll}1 & 2 & 3 & 4 & 5 \\ 1 & 2 & 3 & 4 & 5 \\ 1 & 2 & 3 & 4 & 5 \\ 1 & 2 & 3 & 4 & 5 \\ 1 & 2 & 3 & 4 & 5 \\ 1 & 2 & 3 & 4 & 5 \\ 1 & 2 & 3 & 4 & 5 \\ 1 & 2 & 3 & 4 & 5 \\ 1 & 2 & 3 & 4 & 5 \\ 1 & 2 & 3 & 4 & 5\end{array}$

13. Were there any other problems in your family that concerned you prior to MIT not mentioned above? Yes ( ) No ( )

If so, what were they?

Please rate each problem according to how it has changed for you since MIT.

$\begin{array}{lllll}1 & 2 & 3 & 4 & 5 \\ 1 & 2 & 3 & 4 & 5 \\ 1 & 2 & 3 & 4 & 5 \\ 1 & 2 & 3 & 4 & 5\end{array}$

14. Do you feel that any member or members of your family are the cause of your family problems? Yes ( ) No, the whole family is involved () If "yes," who? 
APPENDIX E

(Page 4)

INTERVIEW SCHEDULE

Case Number

15. Has any family member (or members) left the home since MIT?

1

2

Who?

Where did

they go?

When?

Why?

Have they

returned?

When?

Have they left home more than once?

How many

times?

What was the effect of the absence on the family? (i.e., was it detrimental/helpful?)

1)

2)

3)

16. Has your family, or any member of your family, sought any type of counseling since MIT? Yes ( ) No ( )

For whom was counseling sought? Why?

Was counseling offered for an individual? Yes ( ) No ( ) Who?

The family? Yes ( ) No ( ) Part of the family? Yes ( ) No ( ) Who was involved?

Approximately how many hours of counseling have you had? Are you or other family members still attending counseling sessions? 
APPENDIX E

(Page 5)

INTERVIEW SCHEDULE

Case Number

17. Do you have any suggestions of changes CSD could make to improve their services? 